\title{
Spatially resolved capture of hydrogen sulfide from the water column and sedimentary pore waters for abundance and stable isotopic analysis
}

\author{
D. A. Fike ${ }^{1}$, J.L. Houghton ${ }^{1}$, S. E. Moore ${ }^{1}$, W. P. Gilhooly III' ${ }^{2}$, K. S. Dawson ${ }^{3}$, G. K. Druschel ${ }^{2}$, \\ J. P. Amend ${ }^{4} \&$ V. J. Orphan ${ }^{3}$
}

${ }^{1}$ Dept. of Earth and Planetary Sciences, Washington University, St. Louis, MO 63130, USA; ${ }^{2}$ Dept. of Earth Sciences, Indiana University-Purdue University Indianapolis, Indianapolis, IN 46202, USA; ${ }^{3}$ Div. of Geological \& Planetary Sciences, California Institute of Technology, Pasadena, CA 91125, USA; ${ }^{4}$ Depts. of Earth Sciences and Biological Sciences, University of Southern California, Los Angeles, CA 90089, USA

*Corresponding Author: David A. Fike, 1 Brookings Dr., CB1169, Washington University, St. Louis, MO, 63130, USA; Tel: +1 (314)-935-6607; dfike@levee.wustl.edu;

RUNNING TITLE: Spatially resolved capture of hydrogen sulfide

KEYWORDS: Hydrogen sulfide; sulfur cycling; stable isotopes; sulfur isotopes; photographic film

\begin{abstract}
Sulfur cycling is ubiquitous in sedimentary environments, where it plays a major role in mediating carbon remineralization and impacts both local and global redox budgets. Microbial sulfur cycling is dominated by metabolic activity that either produces (e.g., sulfate reduction, disproportionation) or consumes (sulfide oxidation) hydrogen sulfide $\left(\mathrm{H}_{2} \mathrm{~S}\right)$. As such, improved constraints on the production, distribution, and consumption of $\mathrm{H}_{2} \mathrm{~S}$ in the natural environment will increase our understanding of microbial sulfur cycling. These different microbial sulfur metabolisms are additionally associated with particular stable isotopic fractionations. Coupling measurements of the isotopic composition of the sulfide with its distribution can provide additional information about environmental conditions and microbial ecology. Here we investigate the kinetics of sulfide capture on photographic films as a way to document the spatial distribution of sulfide in complex natural environments as well as for in situ capture of $\mathrm{H}_{2} \mathrm{~S}$ for subsequent stable isotopic analysis. Laboratory experiments and timed field deployments demonstrate the ability to infer ambient sulfide abundances from the yield of sulfide on the films. This captured sulfide preserves the isotopic composition of the ambient sulfide, offset to slightly lower $\delta^{34} \mathrm{~S}$ values by $\sim 1.2 \pm 0.5 \%$ associated with the diffusion of sulfide into the film and subsequent reaction with silver to form $\mathrm{Ag}_{2} \mathrm{~S}$ precipitates. The resulting data enable the exploration of $\mathrm{cm}$-scale lateral heterogeneity that complement most geochemical profiles using traditional techniques in natural environments. Because these films can easily be deployed over a large spatial area, they are also ideal for real-time assessment of the spatial and temporal dynamics of a site during initial reconnaissance and for integration over long timescales to capture ephemeral processes.
\end{abstract}

This is the author's manuscript of the article published in final edited form as:

Fike, D. A., Houghton, J. L., Moore, S. E., Gilhooly, W. P., Dawson, K. S., Druschel, G. K., ... Orphan, V. J. (2017). Spatially resolved capture of hydrogen sulfide from the water column and sedimentary pore waters for abundance and stable isotopic analysis. Marine Chemistry. https://doi.org/10.1016/j.marchem.2017.10.004 


\section{INTRODUCTION}

The biogeochemical sulfur cycle encompasses the aggregate metabolic activity of various microbial pathways (e.g., sulfate reduction, disproportionation, and sulfide oxidation) together with a suite of abiotic reactions (Fike et al., 2015). The sulfur cycle is intimately connected to the global carbon cycle, and thereby climate, through the remineralization of organic carbon. Sulfate reduction in marine sediments is thought to be responsible for the majority of organic matter respiration in many marine sediments (Jørgensen, 1982). The vast majority (>90\%) of the resulting sulfide formed from sulfate reduction in modern marine sediments is typically reoxidized back to sulfate (Jørgensen, 1977) - or intermediate valence sulfur species after interaction, e.g., with iron oxides (Flynn et al., 2014; Hansel et al., 2015). This network of biotic and abiotic reactions can result in spatially heterogeneous sulfur cycling characterized by strong gradients within microbial sediments over spatial scales as small as a few $\mu \mathrm{m}$ (Fike et al., 2008). Recent work has investigated this micro-scale variability by trapping ambient hydrogen sulfide within microbial mats and aggregates on metallic silver disks (Fike et al., 2008; Fike et al., 2009) or wires (Wilbanks et al., 2014), followed by high-resolution analysis using secondary ion mass spectrometry (SIMS). While this approach has provided new insights into small-scale biogeochemical gradients and ecological organization in these environments, it is fundamentally limited by the small size of samples that can be analyzed by SIMS and is difficult to correlate with geochemical and sedimentary data that are often collected over much larger ( $\mathrm{cm}$ to $\mathrm{m}$-scale) intervals.

Here we investigate the use of photographic film as an alternative sulfide capture approach that will integrate micro- and mesoscale observations. In taking this approach, we follow the work of others who have sought to use a variety of silver-based approaches to capture environmental sulfide. For example, Pal et al. (1986) used glass tubes filled with a gelatin-silver nitrate mixture to capture gaseous $\mathrm{H}_{2} \mathrm{~S}$, as insoluble $\mathrm{Ag}_{2} \mathrm{~S}$. Horwell et al. (2004) noted that photographic film, essentially a resin impregnated with silver halide (bromide, iodide or chloride) crystals on an organic backing (e.g., cellulose acetate), should work in a similar manner. Following this, photographic films were used to successfully capture atmospheric (gaseous) $\mathrm{H}_{2} \mathrm{~S}$ at and around volcanic sites (Horwell et al., 2004; Horwell et al., 2005). Like $\mathrm{H}_{2} \mathrm{~S}$ sensors recently developed (Yin et al., 2017), large-format (e.g., dm-sized) photographic films can be used to visually document in the field the presence of hydrogen sulfide and the spatial variability in its abundance (Gilhooly et al., 2014). In addition to the large format, this filmbased approach is beneficial because it is inexpensive and easy to deploy, which allows for the capture of multiple, independent snapshots of dynamic systems, and can accumulate signal over long timescales (up to 24 hours) to capture ephemeral processes. These characteristics are particularly important when investigating complex environmental systems with no a priori knowledge of the scales of their spatial and temporal variability.

The captured sulfide can be analyzed to determine its abundance and isotopic composition. In the case of atmospheric capture, it is possible to quantify the resulting sulfide abundance photometrically (Horwell et al., 2004; Horwell et al., 2005). In aqueous settings, however, it is not possible to reliably use photometric approaches to assess sulfide abundance because of secondary reactions of silver with halides in solution and/or sunlight, both of which can discolor the films. Instead, abundance must be quantified in the laboratory, for example, by extraction of the captured sulfide as acid-volatile sulfide (AVS) (Kaplan and Hulston, 1966). After deployment and retrieval, the films can be sectioned in the laboratory into $\mathrm{mm}$ - or cm-scale strips and subsequent chemical extraction can quantify sulfide concentrations. Moreover, the 
resulting sulfide can be purified as $\mathrm{Ag}_{2} \mathrm{~S}$ for isotopic analysis using traditional isotope ratio mass spectrometry (IRMS) (Fike et al., 2006). Here, we document the kinetics of sulfide uptake onto photographic films and demonstrate the reliability of these films for estimating ambient sulfide concentrations and preserving the sulfur isotopic signature of aqueous sulfide in laboratory experiments. The utility of this approach is then highlighted in a variety of natural settings.

\section{METHODS}

\section{Experimental design}

Black and white film sheets (Ilford Delta 100 Professional) were used in this study. ISO 100 films have the finest grained silver particles and therefore should have the highest rates for chemical sulfide capture and also react the most slowly to ambient sunlight during field deployments. For laboratory experiments, film pieces of $1 \mathrm{~cm} \times 9 \mathrm{~cm}$ were cut in the dark and then soaked in MQ water until all water-soluble dye was removed ( $\sim 10$ minutes for first soak, $\sim 2$ minutes for second soak), rinsed, and dried overnight. Experiments were conducted under anoxic conditions in replicate glass Balch tubes $(\sim 26 \mathrm{~mL})$ sealed with butyl rubber stoppers and sacrificed sequentially at each time step. Balch tubes were covered in foil to prevent reaction with light. Each tube contained a strip of film of known mass and 3 borosilicate beads $(6 \mathrm{~mm}$ diameter) to ensure well-mixed solutions during experiments. Each Balch tube was then filled most of the way with anoxic water (either de-ionized or an artificial seawater solution) with a small headspace to allow the stopper to be put in place. Any remaining headspace and bubbles were removed through a vent needle prior to adding sulfide by displacement with anoxic water stock solution via a small syringe. The de-ionized water or seawater used in each experiment was made anoxic just prior to setting up the tubes by the addition of $2 \mathrm{~mL} / \mathrm{L}$ of reductant ( $1 \mathrm{M}$ ascorbic acid in $2 \mathrm{M}$ sodium hydroxide). This concentration of reductant ( $2 \mathrm{mM})$ was sufficient to reduce the dissolved oxygen in the water and any oxygen from air in the headspace of the Balch tube during assembly. Synthetic seawater was prepared with $25 \mathrm{~g} / \mathrm{L} \mathrm{NaCl}, 1.2 \mathrm{~g} / \mathrm{L}$ $\mathrm{MgCl}_{2} 6 \mathrm{H}_{2} \mathrm{O}, 0.2 \mathrm{~g} / \mathrm{L} \mathrm{NH} \mathrm{NH}_{4}, 0.4 \mathrm{~g} / \mathrm{L} \mathrm{CaCl}{ }_{2} 2 \mathrm{H}_{2} \mathrm{O}, 0.2 \mathrm{~g} / \mathrm{L} \mathrm{NaHCO}_{3}$ in DI water. For experiments at $\mathrm{pH}<11$, the reduced water was also acidified with $\mathrm{HCl}$ so that subsequent addition of the sulfide stock solution $(\mathrm{pH} 11)$ resulted in the desired $\mathrm{pH}$.

The concentrated sodium sulfide stock solution was made fresh for each experiment in a $100 \mathrm{~mL}$ gas-tight glass syringe (Hamilton, USA) in anoxic de-ionized water. A large crystal of $\mathrm{Na}_{2} \mathrm{~S} * 9 \mathrm{H}_{2} \mathrm{O}$ was rinsed in anoxic water to remove any oxidized surface coating, dried, and weighed to obtain the concentration of the stock needed for the planned experimental conditions. Using a syringe adapter, $0.9 \mathrm{~mL}$ of sulfide stock solution was transferred to a $1 \mathrm{~mL}$ gas-tight glass syringe (Hamilton, USA), which was then fitted with a needle. This volume of sulfide was injected quickly through the stopper into the Balch tube, allowing the displaced solution from the tube to exit through a vent needle with a syringe attached. The displaced solution was then discarded and the initial expected concentration in each tube calculated accounting for this dilution. Tubes were agitated with mixing beads to homogenize the solution during the experiments. Although this method creates slight differences between replicate tubes due to differences in volume displaced, we found it maintained the anoxic conditions required to achieve mass balance at each time step. The exposure time for the film in each tube is reported as the time between the injection of sulfide solution and the removal of the film. For each set of experiments, four control tubes, which contained the same initial sulfide concentration but no film, were also assembled. Two controls were sacrificed at the initial time and two at the final 
time to measure any $\mathrm{pH}$ change and assess potential degassing and/or oxidation reactions by comparing the measured sulfide concentration to the expected value.

The procedure for sacrificing each tube depended on the expected concentration of sulfide in solution. For solutions less than $1 \mathrm{mM}$ sulfide, a $1 \mathrm{~mL}$ aliquot was taken and immediately fixed in Cline reagent for sulfide concentration determination (see method below). To facilitate this initial sampling in zero headspace gas-tight tubes, a $1 \mathrm{~mL}$ syringe was flushed and filled with $\mathrm{He}$, which was then injected into the Balch tube, creating slight overpressure and making it easier to pull the sample. Immediately following the removal of this sample, the remaining solution in the Balch tube was fixed with $0.5 \mathrm{~mL}$ of $1 \mathrm{M}$ zinc acetate solution buffered in $1 \mathrm{M}$ acetic acid to prevent sulfide degassing and/or oxidation. The zinc acetate was allowed to completely react with sulfide for 5 minutes before removing the septum. Films were removed from the solution, any $\mathrm{ZnS}$ on its surfaces was rinsed off with de-ionized water into glass serum bottles, along with the remaining solution, and the films were allowed to dry overnight before being processed further.

For experiments conducted at sulfide concentrations higher than $1 \mathrm{mM}$, the solutions needed to be diluted prior to analysis by the Cline (1969) methylene blue method. In these experiments, the sampling procedure at each time was modified by fixing the entire volume in the Balch tube with $0.5 \mathrm{~mL}$ of $1 \mathrm{M}$ zinc acetate, capturing the excess volume in a syringe attached to a vent needle. After 5 minutes, the entire volume, including the excess in the syringe, was then transferred to a serum bottle. Films were separated from the solution and then rinsed into the serum bottle as usual before drying them overnight. The fixed solutions were diluted into a range appropriate for sulfide concentration analysis (see below). In this modified procedure, the extra volume added during rinsing was included in the dilution factor applied to correct the Cline measurement.

\section{Oxidized sulfur compounds}

Experiments were conducted under oxic conditions to test film reactivity with alternate sulfur compounds in solution: sulfite $\left(\mathrm{NaHSO}_{3}, \mathrm{BDH}\right)$, thiosulfate $\left(\mathrm{Na}_{2} \mathrm{~S}_{2} \mathrm{O}_{3} \cdot 5 \mathrm{H}_{2} \mathrm{O}\right.$, Alfa Aesar), tetrathionate $\left(\mathrm{K}_{2} \mathrm{~S}_{4} \mathrm{O}_{6}\right.$, Aldrich), elemental sulfur, and L-cysteine (97\% pure, Aldrich). Elemental sulfur was obtained by acidifying a solution of thiosulfate to cleave the sulfane sulfur. The solid white polymeric sulfur residue was separated and rinsed to remove excess sulfate from the solution and then re-suspended in the appropriate buffered solution; this polymeric elemental sulfur gradually converted over the 5-day exposure to the stable yellow $\mathrm{S}_{8}$ ring solid (Meyer, 1976). Each different sulfur compound was evaluated at two concentrations and with several $\mathrm{pH}$ buffers to simulate the range of environmentally relevant $\mathrm{pH}$ (ranging from 5.5-11). Control films were tested in each buffer solution without any sulfur present. Two film pieces were exposed together in $100 \mathrm{~mL}$ of each solution in the dark for 5 days. Repeat experiments were conducted over 6 hours to simulate a normal field exposure time for those compounds that produced any measurable yield on the films during the 5-day exposure.

\section{Analytical Methods}

The aqueous sulfide concentration was determined by the method of Cline (1969), using either an aliquot taken directly from the Balch tube into the Cline reagent or an aliquot of solution fixed in zinc acetate. Separate Cline reagents were prepared to bracket the range of concentrations expected: reagent 2 [40-250 $\mu \mathrm{M} \mathrm{H}_{2} \mathrm{~S}$ ] made with $8 \mathrm{~g} \mathrm{~N}, \mathrm{~N}$-dimethyl-p-phenylene diamine sulfate and $12 \mathrm{~g}$ ferric chloride in $500 \mathrm{~mL} 6 \mathrm{~N} \mathrm{HCl}$ or reagent 3 [250-1000 $\mu \mathrm{M} \mathrm{H}_{2} \mathrm{~S}$ ] made with $20 \mathrm{~g}$ 
$\mathrm{N}, \mathrm{N}$-dimethyl-p-phenylene diamine sulfate and $30 \mathrm{~g}$ ferric chloride in $500 \mathrm{~mL} 6 \mathrm{~N} \mathrm{HCl}$. The sample $(1 \mathrm{~mL})$ was added to $105 \mu \mathrm{L}$ of the appropriate mixed diamine reagent and allowed to sit for 1 hour. After the color change, this solution was diluted to a final volume of $12.5 \mathrm{~mL}$ (reagent 2) or $50 \mathrm{~mL}$ (reagent 3) with de-ionized water. A $1 \mathrm{~mL}$ aliquot of the diluted solution was transferred to a plastic cuvette and the absorbance at $664 \mathrm{~nm}$ was analyzed on a UV-Vis spectrometer (Thermo Evolution 60). Calibration curves were repeated for each experiment by diluting the stock sulfide solution used in each experiment.

The remainder of the solution from each time step that was previously fixed in zinc was then oxidized to sulfate by reaction with $50 \%$ peroxide in glass containers. After quantitative reaction of the precipitate, the sulfate was converted to barium sulfate by the addition of $\sim 1 \mathrm{~mL}$ $1.8 \mathrm{M} \mathrm{BaCl}_{2}$. The samples were centrifuged, supernatant discarded, and the barium sulfate solid rinsed in de-ionized water and dried for later isotopic analysis.

Silver sulfide captured on the film was extracted using the acid volatile sulfur method (Rickard and Morse, 2005). Sulfide from the films was volatilized with $6 \mathrm{M} \mathrm{HCl}$ on a hot plate (set to $190{ }^{\circ} \mathrm{C}$ ), under a nitrogen stream through a gas-tight extraction line. The gas stream passed through a water trap to prevent any volatile $\mathrm{HCl}$ from reaching the trap vessel. $\mathrm{The}_{2} \mathrm{H}_{2}$ gas then bubbled through a glass tube containing $\sim 10 \mathrm{~mL}$ of $0.1 \mathrm{M}$ zinc acetate solution buffered with acetic acid before being allowed to vent to the atmosphere. The gas stream is bubbled through the zinc acetate trap for 4 hours, which is the minimum time required for our apparatus design to scrub all sulfide out of the water trap. Sulfide concentrations of the trap solutions were determined using the Cline method. The remaining sulfide precipitate was then converted to barium sulfate (as above), rinsed, and dried in preparation for isotopic analysis.

$\underline{\text { Sulfur isotopic analysis }}$

Barium sulfate solids were homogenized prior to weighing $~ 300 \mu \mathrm{g}$ into tin capsules with excess $\mathrm{V}_{2} \mathrm{O}_{5}$. The ${ }^{34} \mathrm{~S} /{ }^{32} \mathrm{~S}$ ratio was analyzed by a Thermo Delta V Plus IRMS following online combustion with a coupled Costech ECS 4010 Elemental Analyzer at Washington University in St. Louis. The sulfur isotopic composition is expressed in standard delta notation as per mil (\%o) deviations from the Vienna Canyon Diablo Troilite (V-CDT) standard. Isotopic measurements were calibrated against 3 in-house standards that have been calibrated against international standards IAEA-S-1, IAEA-S-3, and NBS-127, with analytical errors of $<0.3 \%$ ( $1 \sigma)$ for $\delta^{34}$ S.

\section{RESULTS AND DISCUSSION}

\section{LABORATORY EXPERIMENTS}

Rate of uptake of sulfide on films

Film was exposed to an unbuffered anoxic aqueous sulfide solution in closed gas-tight tubes to evaluate the kinetics of sulfide uptake onto the film and the ability of the films to accurately reflect the in situ sulfide concentration and isotopic composition. The loss of sulfide in solution was balanced by the uptake of sulfide onto the film (Figure 1a) and mass balance of sulfur was conserved during the course of 24 hours, confirming no loss of sulfide due to degassing or oxidation in this experimental design (Table 1). In unbuffered $900 \mu \mathrm{M}$ sulfide solutions with an initial ratio of sulfide to film surface area of $2.6 \pm 0.1 \mu$ mole $\mathrm{S} / \mathrm{cm}^{2}$, the consumption of sulfide was rapid during the first 4 hours of exposure (Figure 1b), gradually slowing with time until they reached an effective saturation point by 8 hours (Figure 1a). The $\mathrm{pH}$ in unbuffered (DI-based) 
sulfide solutions decreased at a constant rate from 11.2 to 10.2 over 24 hours of exposure, likely due to re-speciation of residual sulfide in solution. The $\mathrm{pH}$ consistently dropped by one $\mathrm{pH}$ unit in all unbuffered experiments.

Additional experiments were conducted across a range of initial $\mathrm{pH}$ values and salinities. These experiments were all conducted with a constant initial sulfide concentration and ratio of sulfide to film surface area $\left(\sim 2.6 \mu\right.$ moles $\left.\mathrm{S} / \mathrm{cm}^{2}\right)$. The sulfide uptake rate in DI solutions was reproducible $\left(4.42 \times 10^{-3}\right.$ umoles $\left.\mathrm{S} / \mathrm{cm}^{2} / \mathrm{min}\right)$ at $\mathrm{pH}$ ranging from 5.5 to 11 for a constant initial sulfide concentration $(900 \mu \mathrm{M})$ and film size $(0.245 \mathrm{~g}$ piece) (Figure 2a). These results suggest that the speciation of sulfide $\left(\mathrm{H}_{2} \mathrm{~S}, \mathrm{HS}^{-}, \mathrm{S}^{2-}\right)$ is irrelevant for reaction kinetics (i.e., either all forms react at approximately the same rates or that re-speciation of sulfide occurs faster than the rate of uptake in the case where only one form of sulfide reacts with film). For the same initial conditions, variations in salinity at $\mathrm{pH} 10.5$ resulted in similar uptake rates with a rate constant (k) of $4.32 \times 10^{-6}$ (Figure 2b). For comparison, the rate constant for sulfide uptake on films in DIbased solutions from $\mathrm{pH} 5.5$ to 11 was $5.86 \times 10^{-6}$.

To test the effect of initial sulfide concentration on the rate of uptake onto the film, experiments were conducted at $0.45,0.6,1,2,4$, and $7 \mathrm{mM}$ sulfide (in de-ionized water) and $1 \mathrm{mM}$ at seawater salinity (see Figure 3 for details). Dissolved reduced sulfur phases (e.g., sulfide, polysulfide and the sulfane sulfur of thiosulfate) readily react with silver halide crystals $(\mathrm{AgX})$ imbedded in the film:

$$
\begin{aligned}
& \operatorname{AgX}_{(\mathrm{s})}+\mathrm{H}_{2} \mathrm{~S}_{(\mathrm{aq})}=\mathrm{AgSH}_{(\mathrm{aq})}+\mathrm{H}^{+}+\mathrm{X}_{(\mathrm{aq})}^{-} \\
& \operatorname{AgX}_{(\mathrm{s})}+\mathrm{S}_{2} \mathrm{O}_{3}{ }^{2-}+\mathrm{H}_{2} \mathrm{O}=\mathrm{AgSH}_{(\mathrm{aq})}+\mathrm{SO}_{4}{ }^{2-}+\mathrm{H}^{+}+\mathrm{X}^{-}{ }_{(\mathrm{aq})}
\end{aligned}
$$

With the intermediate complex fixed in the film as solid silver sulfide:

$$
\mathrm{AgX}_{(\mathrm{s})}+\mathrm{AgSH}_{(\mathrm{aq})}=\mathrm{Ag}_{2} \mathrm{~S}_{(\mathrm{s})}+\mathrm{H}^{+}+\mathrm{X}^{-}
$$

In addition, other aqueous sulfide phases (e.g., complexes such as FeS(aq)) would also be expected to react with the films if present, although these are generally not trace phases and therefore not likely to contribute quantitatively to the aggregate sulfide pool captured. If eq. 1 is the rate limiting step, the rate of sulfide uptake onto film is expected to follow second order kinetics, dependent on both silver and sulfide concentrations. The results for low initial sulfide concentrations (e.g., Figure 1b) are more accurately modeled with 2nd order kinetics:

$$
\mathrm{d}\left[\mathrm{H}_{2} \mathrm{~S}\right] / \mathrm{dt}=\mathrm{k}[\mathrm{AgX}]\left[\mathrm{H}_{2} \mathrm{~S}\right]
$$

The concentration of silver halide, while not directly measured, is related to the sulfide lost at time $\mathrm{i}$ as follows:

$$
\begin{gathered}
{[\mathrm{AgX}]_{\mathrm{i}}=[\mathrm{AgX}]_{0}-[\mathrm{AgSH}]_{\mathrm{i}}} \\
\text { where }[\mathrm{AgSH}]_{\mathrm{i}}=\left[\mathrm{H}_{2} \mathrm{~S}\right]_{0}-\left[\mathrm{H}_{2} \mathrm{~S}\right]_{\mathrm{i}}
\end{gathered}
$$

This leads to a rate equation that has both 1 st order and 2 nd order components with respect to sulfide concentration:

$$
\mathrm{d}\left[\mathrm{H}_{2} \mathrm{~S}\right] / \mathrm{dt}=\mathrm{kC}\left[\mathrm{H}_{2} \mathrm{~S}\right]_{\mathrm{i}}+\mathrm{k}\left[\mathrm{H}_{2} \mathrm{~S}_{\mathrm{i}}^{2}\right.
$$




$$
\text { where } \mathrm{C}=[\mathrm{AgX}]_{0}-\left[\mathrm{H}_{2} \mathrm{~S}\right]_{0}
$$

At high initial sulfide concentrations $(>1 \mathrm{mM})$, a 2 nd order rate predicts much faster uptake of sulfide than observed. Instead, a weighted average of 1 st and 2 nd order rate equations provides the best fit, with the weight factor a function of the ratio of sulfide to film area (Figure $3 \mathrm{a}$ ):

$$
\left[\mathrm{H}_{2} \mathrm{~S}\right]_{\mathrm{i}}=\left[\mathrm{H}_{2} \mathrm{~S}\right]_{\mathrm{i}-1}-\left((1-\mathrm{f}) * \mathrm{kC}\left[\mathrm{H}_{2} \mathrm{~S}\right]_{\mathrm{i}-1} * \mathrm{dt}\right)-\left(\mathrm{f} * \mathrm{k}\left[\mathrm{H}_{2} \mathrm{~S}\right]_{\mathrm{i}-1}^{2} * \mathrm{dt}\right)
$$

where the concentration for the current time (i) depends on the concentration in the previous timestep (i-1), the rate constant $\left(\mathrm{k}=4.32 \times 10^{-6}\right)$, the timestep (dt), and the weight factor (f) varies from 1 to 0.27 as a function of increasing initial $\mu$ moles $\mathrm{S} / \mathrm{g}$ film. The empirical rate constant we determined incorporates factors specific to our experimental design (e.g., temperature, film ISO, and surface area). Full understanding of the mechanism that explains a weighted rate expression such as we observe is still unclear. However, this predictable behavior can be used to estimate the minimum time that film should be exposed in the field to accumulate sufficient sulfide for analysis if the approximate porewater sulfide concentration is known. For solutions containing >2 mM sulfide, sulfide uptake effectively stops after $\sim 2.5$ hours (Figure 3a). Even for lower sulfide solutions, the gain in accumulation on the film from longer exposures is fairly small after 4 hours of exposure (Figure 3a).

The uptake curves in Figure $3 \mathrm{a}$ can be used to predict the change in measured sulfide yield on films with time (Figure 3b). It is notable that the offset between the theoretical and observed maximum yield increases and the required exposure time decreases as the initial concentration of sulfide in solution increases (Figure 3). The offset in maximum yield is a constant fraction of the initial sulfide $(0.41 \pm 0.07)$ that represents the effective maximum yield, which is a combination of the concentration in solution and the ratio of the aqueous volume to the surface area of film in our experiments $\left(2.9 \mathrm{~mL} / \mathrm{cm}^{2}\right)$. This is also likely a function of the type of film (ISO) used, as differences in silver halide abundance or crystal size should affect the maximum yield possible. In this study, we used the lowest ISO film (e.g., 100) readily available with the smallest silver halide crystal size. Therefore, to use the yield from films to quantitatively reconstruct sulfide concentrations in situ would require knowledge of sediment porosity and the size of the reservoir replenishing sulfide taken up by the film, information which might not always be possible to obtain. As such, the ability to use these films to reconstruct absolute sulfide abundance in complex natural environments is necessarily somewhat qualitative. However, this limitation does not impact the ability to accurately determine the isotopic composition of the sulfide captured by the film, as demonstrated below.

\section{Isotopic composition of sulfide captured by films}

Sulfide captured on the film can be extracted and purified for abundance and isotopic analysis. For reference, a $1 \mathrm{~cm}^{2}$ piece of film (e.g., $0.5 \times 2 \mathrm{~cm}$ ) with $1 \mu$ mole $\mathrm{S} / \mathrm{cm}^{2}$ sulfide yield will produce $\sim 250 \mu \mathrm{g}$ of $\mathrm{Ag}_{2} \mathrm{~S}$, which is sufficient for stable isotopic $\left(\delta^{34} \mathrm{~S}\right)$ analysis by IRMS. Therefore, film exposed to $<750 \mu \mathrm{M}$ sulfide $\left(\sim 83 \mu \mathrm{M} / \mathrm{cm}^{2}\right)$, even if the exposure time is longer than 4 hours, will require larger pieces of film to be extracted per sample, resulting in correspondingly coarser spatial resolution either in depth or laterally (e.g., 1 x $2 \mathrm{~cm}$ or $0.5 \times 4$ $\mathrm{cm})$. From the initial experiments $(\sim 900 \mu \mathrm{M}$ sulfide, unbuffered $\mathrm{pH}$ in DI solutions), the sulfide captured on the film was depleted relative to coeval aqueous sulfide by an average $1.8 \%$ $( \pm 0.3 \%$ ) (Figure 4$)$. A similar isotopic offset was observed between the solution and film at 
variable $\mathrm{pH}$ in DI solutions of $\sim 900 \mu \mathrm{M}$ sulfide: 1.1 to $1.9 \%$ with an average offset of $1.4 \%$ $( \pm 0.4 \%, 1 \sigma)$ (Table 2$)$. The average isotopic offset in $\sim 800 \mu \mathrm{M}$ sulfide-bearing saline solutions $(12-35 \mathrm{~g} / \mathrm{kg}$ salinity) was not significantly different, with values of $1.0 \%$ o $( \pm 0.8 \%$, $1 \sigma)$ (Table 2$)$. In sum, the average isotopic offset observed between aqueous solution and film is $1.2 \%$ o $( \pm 0.5 \%$, $1 \sigma$ ) and is independent of $\mathrm{pH}$, salinity, and concentration of sulfide (Table 2). Although sulfide uptake rate changes with exposure time and initial sulfide concentration, the isotopic offset appears to remain constant. As such, the sulfide $\delta^{34} \mathrm{~S}$ values from field deployments discussed below have been adjusted for this $1.2 \%$ offset. Thus, photo film is a useful means for easily capturing and subsequently analyzing in situ sulfide $\delta^{34} \mathrm{~S}$ compositions and can be conducted with reasonable field exposure times ( $<4$ hours for in situ sulfide concentrations $>500 \mu \mathrm{M}$; Figure 3b).

\section{Interferences from other sulfur compounds}

Additional sulfur compounds were tested to check for potential capture by the film. Each compound was exposed for 5 days under oxic conditions at a range of $\mathrm{pH}$ and at low and high concentrations (Table 3). Each solution contained two pieces of film ( 0.73 g each) to obtain replicates, although this resulted in the films occasionally obstructing each other. No reaction was observed between the films and sulfite, organic sulfur in the form of cysteine, or any of the buffer solutions used. However, the films exposed to thiosulfate, tetrathionate and elemental sulfur were slightly discolored after 5 days of exposure and yielded sulfide during AVS extractions (Table 3). In addition, for these three compounds the vinyl backing of the film that remained after AVS extraction contained visible quantities of imbedded yellow material.

Repeat experiments using these three intermediate sulfur species were conducted with a single piece of film $(\sim 0.32 \mathrm{~g})$ for a 6-hour exposure to determine if significant interference occurs on timescales more typical of a field deployment. These films showed no discoloration, did not produce any yield during AVS extractions, and did not contain any yellow material in the backing after extraction (data not shown). Thus, we conclude that the risk of these compounds influencing field assays for the abundance and isotopic composition of ambient $\mathrm{H}_{2} \mathrm{~S}$ is very low. However, the presence of yellow material within the film backing after extraction of films deployed in the field could indicate the reaction of partially oxidized sulfur compounds with the films during prolonged exposures in the presence of oxygen.

\section{FIELD APPLICATIONS}

Film-based sulfide capture has utility in a variety of environments where quick field reconnaissance is needed, where in-situ sampling may be challenging, or where intermittent sulfur cycling and/or low sulfide abundance preclude more traditional sampling approaches. Below, we highlight applications of the films for (1) rapid mapping of in situ sulfide distribution in a variety of field settings; (2) confirmation of the lab-based kinetics of sulfide uptake using a time-series of films deployed at submarine methane seeps and the resulting improved determination of in situ porewater chemistry; and (3) in situ high-resolution $\delta^{34} \mathrm{~S}$ isotopic fingerprinting to document spatially and temporally variable sulfur cycling.

\section{Sulfide Mapping}

As a reconnaissance tool, deployment of films is well suited for quick characterization of a variety of environments (Figure 5). Here, we highlight four such examples: finding chemoclines, 
mapping lateral variability, documenting processes along interfaces, and assessing perturbations associated with sampling and/or sample retrieval.

\section{Finding chemoclines: Lake Mahoney, British Columbia}

Mahoney Lake $\left(49^{\circ} 17^{\prime} \mathrm{N} ; 119^{\circ} 35^{\prime} \mathrm{W}\right)$ is a permanently stratified lake in the Okanagan Valley of British Columbia, Canada. It is characterized by anoxic and sulfidic (euxinic) waters below a depth of approximately $7 \mathrm{~m}$ (Gilhooly et al., 2016). The shallowness of the chemocline means that the top of the sulfidic waters are in the photic zone, enabling a dense layer of photosynthetic purple sulfur bacteria to colonize the chemocline (e.g., Figure 5a) (Hamilton, 2014). As a result, sulfide is removed by both phototrophic sulfide oxidation as well as abiotic oxidation with oxygen (Overmann et al., 1996). Here, films can be deployed for a rapid characterization of the position of the chemocline (e.g., Figure 5a). To minimize photochemical production of $\mathrm{Ag}_{(\mathrm{s})}$, the films were mounted ahead of time in the dark and covered during transit to the field and prior to deployment. Metallic silver still reacts with aqueous sulfide (e.g., Fike et al. 2008, 2009), although the kinetics are likely to be different than that observed during the laboratory experiments described here. As can be seen in Figure 5a, the upper boundary of the chemocline is fairly abrupt, spanning a distance of at most a few $\mathrm{cm}$. Locating such a thin interval in the field and reproducibly sub-sampling across it (at $7 \mathrm{~m}$ below the water surface) are inherently challenging. However, as long as the films can be deployed spanning the interval of interest (here a 2-m strip of film was assembled), it is possible to generate spatially resolved records of the chemocline even if the exact location was unknown prior to sampling. As deployed in Lake Mahoney (Figure 5a), the films permit a vertical spatial resolution of $\sim 0.5 \mathrm{~cm}$ for abundance and bulk IRMS analysis, as described above.

\section{Mapping chemoclines: Guerrero Negro, Baja California, Mexico}

The oxic-sulfide chemocline of microbial sediments is a locus of sulfur biogeochemical cycling. Previous work in the microbial mats of Guerrero Negro documented spatially coherent isotopic variations $(\sim 20 \%)$ extending from the chemocline more than $1 \mathrm{~cm}$ into the mat. These isotopic variations were attributed to reflect corresponding variations in microbial sulfate reduction (Fike et al., 2008; Fike et al., 2009), likely due to variable cell-specific sulfate reduction rates (Sim et al., 2011) resulting from the differential availability of electron donors. However, the sulfide capture method previously employed (on 1" metallic silver discs) precluded a robust estimate of variable sulfide concentrations or documenting the spatial extent of these patterns. Using the film-based approach described here, it is possible to document multiple zones of high sulfide abundance with depth in the Guerrero Negro mats (Figure 5b), likely associated with horizons of enhanced sulfate reduction as previously speculated (Fike et al., 2009). Moreover, in multiple films placed more than 1 meter apart (Figure 5b), these intervals are remarkably reproducible, indicating the lateral continuity of these zones across the microbial mat.

\section{Documenting interfacial processes: Frasassi Gorge, Italy}

In some microbial mat environments, the presence of sulfide within the water column allows additional processes to be investigated. In the microbial mats of Guerrero Negro, stagnant waters at night allowed for the accumulation of sulfide in the water column. Under these conditions, microbial sulfide oxidation at the surface of the mats drew down sulfide diffusing from both above and below (Fike et al., 2009). Similar processes can be observed at the Frasassi Gorge, Italy. Here, the sulfidic waters from the Frasassi Cave complex (Galdenzi et al., 2008) enter the 
adjacent Sentino river, resulting in a complex microbial community dominated by sulfide oxidizers and cyanobacteria (Klatt et al., 2016). Films deployed in this system document abundant sulfide both in the sediments and in the flowing water column (Figure 5c). However, at the sediment water interface, negligible sulfide is trapped by the film as the sulfide-oxidizing bacteria effectively outcompete capture by the film (Figure 5c), as was found at the microbial mats in Guerrero Negro (Fike et al., 2009).

\section{Identification of sampling artifacts: Costa Rica Margin}

In field sampling, many processes can alter signals such that what is ultimately analyzed is not representative of the system under study. One such example is the collection of core samples from advective systems. The loss of advective flow upon sampling means that when these cores are subsequently analyzed for their geochemical profiles in the laboratory, the results may no longer reflect in situ conditions. This is true, e.g., in many shallow marine hydrothermal systems, highlighting the need for in situ analysis (e.g., Gilhooly et al., 2014).

Similar challenges can arise during shipboard analysis of sediment cores collected from the deep ocean. Here sampling artifacts can include potential degassing of volatile phases associated with sediment coring and subsequent retrieval from depth as the cores are brought to atmospheric pressure. Figure 5d shows a film deployed in the middle of a pushcore incubated in situ at active methane seeps at Jaco scarp (cruise AT 15-44) along the Costa Rica margin (Sahling et al., 2008). Although this core came from an area with no sulfide in the water column prior to sampling, by the time the film was processed immediate after its return to the ship, the film exposed in the water phase above the sediments in the push core had reacted with sulfide (Figure 5d). This unexpected sulfide signal shows the impact of $\mathrm{H}_{2} \mathrm{~S}$ release during recovery at depth or subsequent transport, but prior to processing in the shipboard laboratory. Such perturbations following sample collection could plausibly impact a range of porewater geochemical (and microbiological) parameters analyzed shipboard (or subsequently in laboratories on land). The deployment of films on the exterior of cores (eliminating potential artifacts from core-top water during ascent and recovery) as well as the in situ deployment and removal of films prior to ascent can be used to ground truth resulting porewater data (see below).

\section{Kinetics and porewater determinations: Santa Monica Basin, California}

Submarine methane seeps, and the spatially and ecologically complex ecosystems that they support, are critical components in the global carbon cycle. Reconstructing in situ processes in cores taken from depth and analyzed ex situ aboard a ship or in a laboratory back on land is inherently challenging and runs the risk that the system(s) under study may not reflect their in situ characteristics, e.g., due to degassing prior to sampling and porewater oxidation prior to analysis. However, the film approach described here is ideal for in situ field deployments.

To explore the use of these films to capture sulfide isotope depth profiles in methane seep sediments, we conducted a series of film deployments at a methane mound in the Santa Monica Basin off of Southern California (Paull et al., 2008). This mound was located at $33^{\circ} 47.331 ; 118^{\circ}$ 40.0970 at a depth of $860 \mathrm{~m}$ with an in situ temperature of approximately $5^{\circ} \mathrm{C}$. Films were deployed in seep sediments covered by expansive orange and white sulfur-oxidizing microbial mats. Push cores with films on the exterior were inserted in the mat-covered sediments in close proximity to each other ( 4-5 cm spacing) and successively removed from the sediments after a 2 minute, 2 hour, 4 hour, and 24 hour in situ incubation period. The shortest exposure time (2 
min) preserves visible fine-scale spatial variability in the surface sediments (Figure 6a). Although the sulfide yield is low, the isotopic composition preserved by the film is robust when compared to longer exposure times (Figure 6a). Visual inspection of both the front and back sides of films in the field enabled rapid assessment of the approximate amount of sulfide captured, with increasing sulfide levels precipitated corresponding to the opacity observed on the backside of film (Figure 6b,c). For example, the back of the film incubated for 2 hours shows a gradual increase in darkness corresponding to yield with depth, while the 4-hour film has a sharp change on the back with a correspondingly sharp increase in yield (Figure 6b,c). The 24-hour exposure saturated the film and artifacts related to seawater interactions with the film began to appear near the sediment-water interface, as indicated by the metallic sheen on the film surface (Figure 6d). Saturation of the film does not significantly alter the isotope profile preserved (Figure 6d). The yield from intermediate exposure times ( 2 and $4 \mathrm{hrs}$ ) is used to test the empirically derived kinetics of film sulfide capture. Extrapolating from Figure $3 b$, the yields from the film exposed for 4 hours appear to have reached the effective saturation at all depths, while the 2-hour exposure had not. Using the relationships between initial sulfide concentration and film yield from Figure 3b, the predicted in situ sulfide profile for the 2-hour exposure matches the general shape of the porewater sulfide profile measured in the corresponding pushcore sediments (Figure 7a). The 4-hour exposure replicates this in situ profile despite the film reaching its maximum yield. Moreover, upon subsequent isotopic analysis, these films generate reproducible $\delta^{34} \mathrm{~S}$ profiles down core (Figure 7c-d), documenting the steep geochemical gradients associated with these systems.

Additionally, the 4-hour exposure provides an independent assessment of how sediment samples may be altered between collection and shipboard analysis. Specifically, in the extracted porewater profiles from the core associated with the 4-hour incubation, there is a marked decrease in porewater sulfide at depth without a corresponding increase in porewater sulfate (Figure 7b). This result is counterintuitive and inconsistent with the abundance of sulfide captured on the films. Together, this suggests that the porewater sulfide profile for this core is impacted by sulfide oxidation during shipboard porewater extraction.

\section{Spatially and temporally variable sulfur cycling: Milos, Greece}

Milos is a volcanic island located along the Hellenic Volcanic Arc in the Aegean Sea. Palaeochori Bay, on the southeastern part of the island, is characterized by abundant, shallow-sea (5-20 $\mathrm{m} \mathrm{depth)}$ hydrothermal venting, manifest both as areas of free gas discharge and diffusively venting geothermal fluids (Dando et al., 1995). Hydrothermal activity varies strongly on short spatial and temporal scales, resulting in a heterogeneous patchwork of actively and diffusively venting sites amid background shallow marine sediment (Wenzhöfer et al., 2000; Yücel et al., 2013). For example, the temperature of pore fluids at $10 \mathrm{~cm}$ depth closest to the venting areas range from $25-75^{\circ} \mathrm{C}$ on different days relative to those in background sediments $\left(\sim 20^{\circ} \mathrm{C}\right)$ either beneath seagrass stands or far from visible effects of hydrothermal venting. The interaction between reduced, $\mathrm{H}_{2} \mathrm{~S}$-rich hydrothermal fluids and cooler, oxic seawater results in both abiotic and microbial sulfide oxygen, the latter supporting a diverse population of sulfide oxidizing bacteria, and is associated with the precipitation of a range of sulfide minerals (Brinkhoff et al., 1999; Sievert et al., 1999; Bayraktarov et al., 2013).

At Milos, hydrogen sulfide is abundant at actively venting sites both in free gas (up to 5 $\mathrm{wt} \%$ ) as well as dissolved in the hydrothermal fluids (up to several $\mathrm{mM}$ ). Previous work has documented the abundance and isotopic composition of hydrogen sulfide in these hydrothermal 
fluids and sedimentary porewaters (Gilhooly et al., 2014). Deployment of a network of films provides a means to capture ephemeral patterns in the spatial and temporal distribution of sulfide within these sediments and the overlying water column (Figure 8). Moreover, given the multiple sources of sulfide (abiogenic hydrothermal and the product of microbial sulfate reduction), these shallow sediments are ideal for investigating the interface(s) between abiotic and biotic regimes, as recorded in the stable isotopic composition of the sulfide captured in the films. Initial results of $\mathrm{H}_{2} \mathrm{~S}$ analyzed from a range of porewaters at vent sites had a narrow $\delta^{34} \mathrm{~S}$ distribution (2-3\% ), consistent with a single hydrothermal source (Gilhooly et al., 2014). By deploying films for prolonged intervals (e.g., 4-16 hours) repeatedly over several days and including peripheral areas less affected by hydrothermal discharge, it is possible to capture evidence of the temporal variability of subsurface advection. This sampling strategy revealed highly variable sulfide abundances with time, even in sediments proximal to active venting, as well as very patchy sulfide distribution within more distal sediments (Figure 8a-d). Even slightly discolored films (Figure 8c) captured enough sulfide for isotopic analysis (Figure 8e). Analysis of these films indicates a ${ }^{32} \mathrm{~S}$-depleted component of captured sulfide derived from biological sulfate reduction is present even within hydrothermally impacted sediments (Figure 8f). However, evidence of biological activity is intermittent and interspersed with the spatially variable background hydrothermal input, as seen in longer exposures that capture the $\delta^{34} \mathrm{~S}$ record even in low sulfide concentration fluids (Figure 8c,f). Given the likely fine-scale spatial organization of the microbial communities in these environments, higher-resolution analyses could be a useful approach to explicitly map these areas and their sulfide isotopic composition and document the heterogeneity of biogenic vs. abiogenic sulfide in these ephemeral systems.

\section{CONCLUSIONS}

A film-based approach provides the ability to reconstruct the in situ abundance and isotopic composition of ambient hydrogen sulfide in the water column and porewaters over large areas. This approach is useful for reconnaissance of large and/or dynamic systems (e.g., such as hydrothermal vent environments or methane seeps) as well as for detailed study of systems with steep geochemical gradients (i.e., chemoclines) that might otherwise be logistically challenging to sample (e.g., sulfide lakes and/or microbial mat systems). Laboratory experiments and timed field deployments demonstrate the ability to infer ambient sulfide abundances from the yield of sulfide on the films. This captured sulfide preserves the isotopic composition of the ambient sulfide, offset to slightly lower $\delta^{34} \mathrm{~S}$ values by $\sim 1.2 \pm 0.5 \%$ associated with the diffusion of sulfide into the film and subsequent reaction with silver to form $\mathrm{Ag}_{2} \mathrm{~S}$ precipitates. The resulting isotopic data can be collected at $\sim 0.5 \mathrm{~cm}$ resolution using traditional gas source mass spectrometry, while higher-resolution analyses are possible using either laser-ablation (Goodridge and Valentine, 2016) or secondary ion mass spectrometry (Fike et al., 2009; Wilbanks et al., 2014) techniques. Together with additional methods to assess ambient sulfide under development (Yin et al., 2017), these approaches provide a way to link meso-scale geochemical profiles down to the micron-scale metabolic activity that drives them.

\section{ACKNOWLEDGMENTS}

This research was supported by NSF funding to DAF (OCE-1061476; OCE-1155346; EAR1124389) and by the Gordon and Betty Moore Foundation through Grant GBMF3306 to the 
California Institute of Technology. We are also indebted to the NASA Ames group (K. Turk, M. Kubo, L. Jahnke and D. Des Marais), A. Dekas, J. Glass, R. Price, F.-C. Kafantaris, and J. Macalady for support and assistance with sample collections. This manuscript benefited from reviews by R. C. Aller and one anonymous reviewer. 


\section{REFERENCES}

Bayraktarov, E., Price, R.E., Ferdelman, T.G., Finster, K., 2013. The pH and pCO2 dependence of sulfate reduction in shallow-sea hydrothermal CO2-venting sediments (Milos Island, Greece). Frontiers in Microbiology, 4: 1 - 10.

Brinkhoff, T., Sievert, S.M., Kuever, J., Muyzer, G., 1999. Distribution and Diversity of SulfurOxidizing Thiomicrospira spp. at a Shallow-Water Hydrothermal Vent in the Aegean Sea (Milos, Greece). Appl. Environ. Microbiol., 65: 3843 - 3849.

Cline, J. D., 1969. Spectrophotometric determination of hydrogen sulfide in natural waters. Limnology and Oceanography, 14: 454-458.

Dando, P.R., Hughes, J.A., Leahy, Y., Niven, S.J., Taylor, L.J., Smith, C., 1995. Gas venting rates from submarine hydrothermal areas around the island of Milos, Hellenic Volcanic Arc. Continental Shelf Research, 15: 913 - 929.

Fike, D.A., Bradley, A.S., Rose, C.V., 2015. Rethinking the Ancient Sulfur Cycle. Annual Review of Earth \& Planetary Sciences, 43: 20.1 - 20.30.

Fike, D.A., Finke, N., Zha, J., Blake, G., Hoehler, T.M., Orphan, V.J., 2009. The effect of sulfate concentration on (sub)millimeter-scale sulfide $\delta 34 \mathrm{~S}$ in hypersaline cyanobacterial mats over the diel cycle. Geochimica et Cosmochimica Acta, 73: 6187 - 6204.

Fike, D.A., Gammon, C.L., Ziebis, W., Orphan, V.J., 2008. Micron-scale mapping of sulfur cycling across the oxycline of a cyanobacterial mat: a paired nanoSIMS and CARDFISH approach. ISME Journal, 2: 749 - 759.

Fike, D.A., Grotzinger, J.P., Pratt, L.M., Summons, R.E., 2006. Oxidation of the Ediacaran Ocean. Nature, 444(7 December 2006): 744 - 747.

Flynn, T.M., O'Loughlin, E.J., Mishra, B., DiCristina, T.J., Kemner, K.M., 2014. Sulfur-Mediated Electron Shuttling During Bacterial Iron Reduction. Science, 344(6187): 1039 1042.

Galdenzi, S., Cocchioni, M., Morichetti, L., Amici, V., Scuri, S., 2008. Sulfidic ground-water chemistry in the Frasassi Caves, Italy. Journal of Cave and Karst Studies, 70: 94 107.

Gilhooly, W.P., Fike, D.A., Druschel, G.K., Price, R.E., Amend, J.P., 2014. Sulfur and oxygen isotope insights into sulfur cycling in shallow-sea hydrothermal vents. Geochemical Transactions, 15: 12 .

Gilhooly, W.P., Reinhard, C.T., Lyons, T.W., 2016. A comprehensive sulfur and oxygen isotope study of sulfur cycling in a shallow, hyper-euxinic meromictic lake. Geochim. et Cosmochim. Acta, 189: 1 - 23.

Goodridge, B.M., Valentine, D.L., 2016. Microscale Measurement and Visualization of Sulfide 834S Using Photographic Film Sulfide Capture Coupled with Laser Ablation Multicollector Inductively Coupled Plasma Mass Spectrometry. Analytical Chemistry, 88: 10126 - 10133.

Hamilton, T.L., Bovee, R. J., Thiel, V., Sattin, S. R., Mohr, W., Schaperdoth, I., Vogl, K., Gilhooly, W. P., Lyons, T. W., Tomsho, L. P., Schuster, S. C., 2014. Coupled reductive and oxidative sulfur cycling in the phototrophic plate of a meromictic lake. Geobiology, 12(5): $451-468$.

Hansel, C.M., Lentini, C.L., Tang, Y., Johnston, D.T., Wankel, S.D., 2015. Dominance of sulfurfueled iron oxide reduction in low sulfate freshwater sediments. ISME Journal, 9: $2400-2412$. 
Horwell, C.J., Allen, A.G., Mather, T.A., Patterson, J.E., 2004. Evaluation of a novel passive sampling technique for monitoring volcanogenic hydrogen sulfide. Journal of Environmental Monitoring, 6: 630 - 635.

Horwell, C.J., Patterson, J.E., Gamble, J.A., Allen, A.G., 2005. Monitoring and mapping of hydrogen sulphide emissions across an active geothermal field: Rotorua, New Zealand. Journal of Volcanology and Geothermal Research, 139: 259 - 269.

Jørgensen, B.B., 1977. The sulfur cycle of a coastal marine sediment (Limfjorden, Denmark). Limnology and Oceanography, 22(5): 814 - 832.

Jørgensen, B.B., 1982. Mineralization of organic matter in the sea bed-the role of sulphate reduction. Nature, 296: 643 - 645.

Kaplan, I.R., Hulston, J.R., 1966. The isotopic abundance and content of sulfur in meteorites. Geochim. et Cosmochim. Acta, 30(5): 479 - 496.

Klatt, J.M., Meyer, S., Häusler, S., Macalady, J.L., de Beer, D., Polerecky, L., 2016. Structure and function of natural sulphide-oxidizing microbial mats under dynamic input of light and chemical energy. ISME Journal, 10(4): 921 - 933.

Overmann, J., Beatty, J.T., Krouse, H.R., Hall, K.J., 1996. The sulfur cycle in the chemocline of a meromictic salt lake. Limnology and Oceanography, 41(1): 147 - 156.

Pal, T., Ganguly, A., Maity, D.S., 1986. Use of a silver-gelatin complex for the microdetermination of hydrogen sulphide in the atmosphere. Analyst, 111: 691 693.

Paull, C.K., Normark, W.R., Ussler, W., Caress, D.W., Keaten, R., 2008. Association among active seafloor deformation, mound formation, and gas hydrate growth and accumulation within the seafloor of the Santa Monica Basin, offshore California. . Marine Geology, 250: 258 - 275.

Rickard, D., Morse, J.W., 2005. Avid-volatile sulfide (AVS). Marine Chemistry, 97: 141-197.

Sahling, H., Masson, D.G., Ranero, C.R., Huehnerbach, V., Weinrebe, W., Klaucke, I., Buerk, D., Brueckmann, W., Suess, E., 2008. Fluid seepage at the continental margin offshore Costa Rica and southern Nicaragua. Geochem. Geophys. Geosyst., 9: Q05S05.

Sievert, S.M., Brinkhoff, T., Muyzer, G., Ziebis, W., Kuever, J., 1999. Spatial Heterogeneity of Bacterial Populations along an Environmental Gradient at a Shallow Submarine Hydrothermal Vent near Milos Island (Greece). Appl. Environ. Microbiol., 65: 3834 3842.

Sim, M.S., Bosak, T., Ono, S., 2011. Large Sulfur Isotope Fractionation Does Not Require Disproportionation. Science, 333: 74 - 77.

Wenzhöfer, F., Holby, O., Glud, R.N., Nielsen, H.K., Gundersen, J.K., 2000. In situ microsensor studies of a shallow water hydrothermal vent at Milos, Greece. Marine Chemistry, 69: 43 - 54.

Wilbanks, E.G., Jaekel, U., Salman, V., Humphrey, P.T., Eisen, J.A., Faccioti, M.T., Buckley, D.H., Zinder, S.H., Druschel, G.K., Fike, D.A., Orphan, V.J., 2014. Microscale sulfur cycling in the phototrophic pink berry consortia of the Sippewissett Salt Marsh. Environmental Microbiology, 16(11): 3398 - 3415.

Yin, H., Zhu, Q., Aller, R.C., 2017. An Irreversible Planar Optical Sensor for MultiDimensional Measurements of Sedimentary $\mathrm{H}_{2} \mathrm{~S}$. Marine Chemistry, in press.

Yücel, M., Sievert, S.M., Vetriani, C., Foustoukos, D.I., Giovannelli, D., Le Bris, N., 2013. Ecogeochemical dynamics of a shallow-water hydrothermal vent system at Milos Island, Aegean Sea (Eastern Mediterranean). Chemical Geology, 356: 11 - 20. 


\section{FigURES}

Figure 1: (A) Results of time series experiments demonstrate mass balance of sulfide between solution (black circles) and film (red squares) during uptake onto the film over 22 hours of exposure $(n=6, \pm 1 \sigma)$. Data shown is the average of 6 time-series experiments conducted in unbuffered DI solutions at $\mathrm{pH} 11$ with an initial sulfide concentration of $900 \mu \mathrm{M}$. (B): Uptake of sulfide onto the film over the first 4 hours of exposure. This uptake follows second-order kinetics (solid line) rather than simple first order (dashed line).

Figure 2: (A) Experiments at initial sulfide concentration of $900 \mu \mathrm{M}$ and film piece of $1.5 \times 6 \mathrm{~cm}$ $(0.245 \mathrm{~g})$ show reproducible sulfide uptake at $\mathrm{pH}$ ranging from 5.5 to 11. (B) Experiments at the same initial conditions with variable salinity $(0,11,17,23$, and $35 \mathrm{mg} / \mathrm{L}$ salinity) also show reproducible sulfide uptake that follows second order kinetics. The second-order kinetics observed result in a predictable linear relationship between the inverse concentration and time, with a single slope representing the rate constant $\left(\mathrm{k}=4.32^{*} 10^{-6}\right)$ for the range of conditions examined.

Figure 3: (A) Loss of sulfide from solution indicates that sulfide uptake on films follows a combinatin of first and second order kinetics in DI solutions over a range of starting concentrations: $7000 \mu \mathrm{M}$ (red circles), $4000 \mu \mathrm{M}$ (orange diamonds), $900 \mu \mathrm{M}$ (blue diamonds), $600 \mu \mathrm{M}$ (green squares), $500 \mu \mathrm{M}$ (orange circles). Experiments at $35 \mathrm{mg} / \mathrm{L}$ salinity at $800 \mu \mathrm{M}$ initial sulfide (red triangles) also follow the same kinetics. Films reach an effective saturation after a period of time that is specific to the conditions in these experiments $(26 \mathrm{~mL}$ solution with a $9 \mathrm{~cm}^{2}$ piece of film of $0.245 \mathrm{~g}$ ). The maximum loss of sulfide from solution is $\sim 1000-2000 \mu \mathrm{M}$ sulfide at the conditions tested. The portion of reaction following a first order rate relative to a second order rate changes slightly as a function of sulfide ( $\mu$ moles) in solution relative to film size (see text). (B) Corresponding yield of sulfide captured by the films. Over time, sulfide uptake effectively stops at these conditions (transition from solid to dashed lines). The maximum sulfide yield on the film for these volume:surface area conditions is $41 \%$ of the initial sulfide concentration and the time to reach the maximum yield scales with initial sulfide concentration.

Figure 4: Isotopic compositions of sulfide extracted from film with the corresponding sulfide remaining in solution for the experiments shown in Figure 1 and Table 1. The isotopic fractionation is constant over the exposure time, with an average offset of $1.8 \%$ o $( \pm 0.3 \%, 1 \sigma)$.

Figure 5: Field deployment for visualization of sulfide. A) Photo of Lake Mahoney field sampling and syringe capture. The film clearly documents the position of the chemocline. Parallel sampling of the water column every $10 \mathrm{~cm}$ vividly shows the location of the photosynthetic purple sulfur bacteria growing along the chemocline. Syringe sampling system designed and built by W. P. Gilhooly. (B) Films placed within the thick laminated microbial mats in hypersaline ponds (Guerrero Negro, Baja California, Mexico) record layers of sulfiderich porewaters within the mat that are attributed to zones of enhanced rates of microbial sulfate reduction. The scale bar represents $2.5 \mathrm{~cm}$ and the two films were deployed $>1 \mathrm{~m}$ apart in the mat, demonstrating the lateral reproducibility of these zones within the mat. (C) Film placed into sediments covered in white microbial streamers at Frasassi Gorge, Italy. The surficial sediments are dominated by sulfur oxidizers that scavenge sulfide at the sediment surface where microbial 
density is highest. (D) Film placed inside a pushcore retrieved from the seafloor at Jaco Scarp on the Costa Rica Margin. The sample was collected under an oxic water column, but during sampling, ascent, and transport to the laboratory, degassing resulted in $\mathrm{H}_{2} \mathrm{~S}$ release to the water column where it reacted with the films. These processes disturb geochemical gradients prior to shipboard measurements, resulting in signals that may not reflect in situ processes and conditions.

Figure 6: Adjacent films deployed in methane seep sediments of Santa Monica Basin, California for (A) 2 minutes, (B) 2 hours, (C) 4 hours, and (D) 24 hours show visible differences on the front and back of each film. The scale bar is $1 \mathrm{~cm}$. Film yield in $\mu \mathrm{mol} \mathrm{S} / \mathrm{g}$ film is shown as solid squares and $\delta^{34} \mathrm{~S}$ of the sulfide captured on the film is shown as open circles. The extracted yields are shown below each film, all on the same x-axis. Note: inset on the 2-minute exposure time shows even small yields from brief incubations can be quantified.

Figure 7: The in situ sulfide concentration from films (red squares, upper x-axis) is compared to the porewater sulfide (blue circles) and sulfate (green squares) on the lower x-axis. The depth profile recorded by film matches the shape of the profile from the sediment core in the 2-hour exposure (A). The 4-hour exposure film (B) reproduces the profile in (A), however, the sulfide profile for the deeper sediments from this core was compromised during retrieval and/or sampling, as indicated by loss of sulfide at depth with no corresponding increase in the sulfate profile. Depth profiles of $\delta^{34} \mathrm{~S}$ of sulfide from replicate films exposed for 2 hours (C) and for 4 hours (D) demonstrate good reproducibility of general trends but also capture fine-scale detail that changes with location.

Figure 8: Paired abundance and isotopic records document spatially and temporally varying processes. (A-D) Films exposed in sediments at and near hydrothermal vents in Palaeochori Bay offshore of Milos, Greece. The visual appearance of films is variably patchy, frequently with highest abundances right at or above the sediment water interface (marked with dashed lines). Scale bars in each photo are $1 \mathrm{~cm}$. The $\mathrm{pH}$ at $10 \mathrm{~cm}$ depth was fairly consistent between sampling locations in A-D, ranging from 4.4 to 5.2. However, temperature fluctuates constantly in this system. At $10 \mathrm{~cm}$ depth, for example, temperature recorded at deployment and recovery ranged from 44 to $38^{\circ} \mathrm{C}$ in (A), 20 to $39.5^{\circ} \mathrm{C}$ in (B), and 22.6 to $55.4^{\circ} \mathrm{C}$ in (D). Temperature was only recorded on recovery at $27.2^{\circ} \mathrm{C}$ in (C). The film amalgam is not stable at high temperatures and was occasionally completely removed at depth (e.g., D). (E-F) Sulfide abundance and isotopic composition for (A-D), color coded by film. (E) Sulfide abundance captured by film is variable and still measurable even on lightly discolored films such as in (C). (F) Hydrothermal sulfide $\delta^{34} \mathrm{~S}$ is consistently 2-3\%o in different vent areas (Gilhooly et al., 2014) and is indicated by grey shading. Evidence of microbial sulfate reduction (resulting in depleted $\delta^{34} \mathrm{~S}$ values) is ephemeral and likely impacted by variations in the local advection of hydrothermal fluids. 
Table 1: Unbuffered experiments of film exposed to sulfide solutions in freshwater (values are averaged from 6 complete time-series experiments at these conditions).

\begin{tabular}{|c|c|c|c|c|c|c|c|}
\hline $\begin{array}{l}\text { Time } \\
\text { (min) }\end{array}$ & $\begin{array}{c}\text { Fraction } \\
\mathrm{H}_{2} \mathrm{~S} \\
\text { uptake }\end{array}$ & $\begin{array}{l}\mu \mathrm{M} S \text { in } \\
\text { solution }\end{array}$ & $\begin{array}{l}\mu \text { moles } \\
\text { S/g film }\end{array}$ & $\begin{array}{c}\% \\
\text { recovery }\end{array}$ & $\begin{array}{c}\delta^{34} \mathrm{~S} \\
\text { solution } \\
\underset{(\% o)^{*}}{*}\end{array}$ & $\begin{array}{c}\delta^{34} \mathrm{~S} \text { film } \\
\left(_{(\% o}^{*}\right)^{*}\end{array}$ & $\begin{array}{c}\text { Isotopic } \\
\text { offset } \\
(\%)^{* \#}\end{array}$ \\
\hline 0 & 0 & 895 & 88.3 & 99.8 & 20.0 & n.d. & n.d. \\
\hline 20 & 0.11 & 823 & 85.3 & 102.7 & 20.3 & n.d. & n.d. \\
\hline 31 & 0.18 & 796 & 78.8 & 96.9 & 20.3 & 18.0 & 2.3 \\
\hline 45 & 0.20 & 734 & 76.4 & 95.1 & 20.1 & 18.1 & 2.0 \\
\hline 60 & 0.26 & 713 & 71.5 & 95.5 & 20.4 & 18.5 & 2.0 \\
\hline 73 & 0.26 & 666 & 71.0 & 97.1 & 20.4 & 18.6 & 1.8 \\
\hline 97 & 0.33 & 681 & 65.2 & 94.5 & 20.3 & 18.8 & 1.5 \\
\hline 120 & 0.38 & 647 & 64.0 & 100.4 & 20.2 & 18.8 & 1.4 \\
\hline 148 & 0.41 & 607 & 64.2 & 97.1 & 20.3 & 18.6 & 1.8 \\
\hline 186 & 0.43 & 615 & 56.7 & 96.7 & 20.2 & 18.5 & 1.7 \\
\hline 239 & 0.52 & 593 & 54.4 & 97.0 & 20.7 & 19.0 & 1.7 \\
\hline 360 & 0.65 & 572 & 46.3 & 87.1 & 20.7 & 19.2 & 1.5 \\
\hline 479 & 0.69 & 530 & 33.1 & 82.3 & 20.7 & 18.6 & 2.1 \\
\hline 600 & 0.70 & 508 & 28.7 & 84.7 & 20.8 & 19.5 & 1.3 \\
\hline 863 & 0.71 & 494 & 28.1 & 88.7 & 20.3 & 18.6 & 1.7 \\
\hline 1039 & 0.73 & 434 & 29.8 & 92.8 & 20.1 & 19.4 & 0.7 \\
\hline 1236 & 0.77 & 430 & 25.9 & 93.2 & n.d. & n.d. & n.d. \\
\hline
\end{tabular}

n.d.: $\delta^{34} \mathrm{~S}$ could not be determined when $\mathrm{BaSO}_{4}$ yield was insufficient for IRMS analysis.

${ }^{\#}$ The average offset of $\delta^{34} \mathrm{~S}$ between solution and film for these experiments is $1.8 \%$ (s.d. $0.3 \%$ ). 
Table 2: Average isotopic offset between film and solution from experiments at variable $\mathrm{pH}$ and salinity.

\begin{tabular}{|c|c|c|c|c|c|}
\hline \multicolumn{3}{|c|}{ Condition } & \multirow{2}{*}{$\begin{array}{c}\text { mean isotopic } \\
\text { offset } \\
\left(\delta^{34} S_{\text {solution }}-\right. \\
\left.\delta^{34} S_{\text {film }}\right)\end{array}$} & \multirow{2}{*}{$\begin{array}{c}\text { Standard } \\
\text { deviation of } \\
\text { isotopic offset }^{*} \\
(1 \sigma)\end{array}$} & \multirow{2}{*}{$\begin{array}{c}\text { n of paired } \\
\text { measurements } \\
\text { (solution - film) }\end{array}$} \\
\hline $\mathbf{p H}$ & $\begin{array}{l}\text { Salinity } \\
\text { (mg/L) }\end{array}$ & $\begin{array}{c}\mathrm{H}_{2} \mathrm{~S} \\
(\mathrm{mM})\end{array}$ & & & \\
\hline 5.5 & 0 & 1 & 1.86 & 0.13 & 4 \\
\hline 7.1 & 0 & 1 & 1.19 & 0.06 & 4 \\
\hline 7.7 & 0 & 1 & 1.15 & 0.37 & 6 \\
\hline 8.7 & 0 & 1 & 1.11 & 0.15 & 7 \\
\hline 11 & 0 & 1 & 1.78 & 0.28 & 7 \\
\hline \multicolumn{3}{|c|}{ average all pH } & 1.36 & 0.40 & \\
\hline 10.5 & 11 & 1 & 1.03 & 0.64 & 5 \\
\hline 10.5 & 23 & 1 & 1.40 & 0.78 & 3 \\
\hline 10.5 & 35 & 1 & 0.83 & 1.03 & 8 \\
\hline \multicolumn{3}{|c|}{ average all salinities } & 1.09 & 0.29 & \\
\hline 11 & 0 & 4 & 1.01 & 0.43 & 4 \\
\hline 11 & 0 & 7 & 0.71 & 0.44 & 8 \\
\hline \multicolumn{3}{|c|}{ Average all conditions } & 1.21 & 0.5 & \\
\hline
\end{tabular}

Standard deviation is calculated using all time points for which paired solution and film isotopic composition was determined. 
Table 3: Sulfur uptake onto film after 5-day exposures to intermediate redox sulfur compounds reported as $\mu \mathrm{mol} \mathrm{S} / \mathrm{g}$ film. Replicates are reported when available.

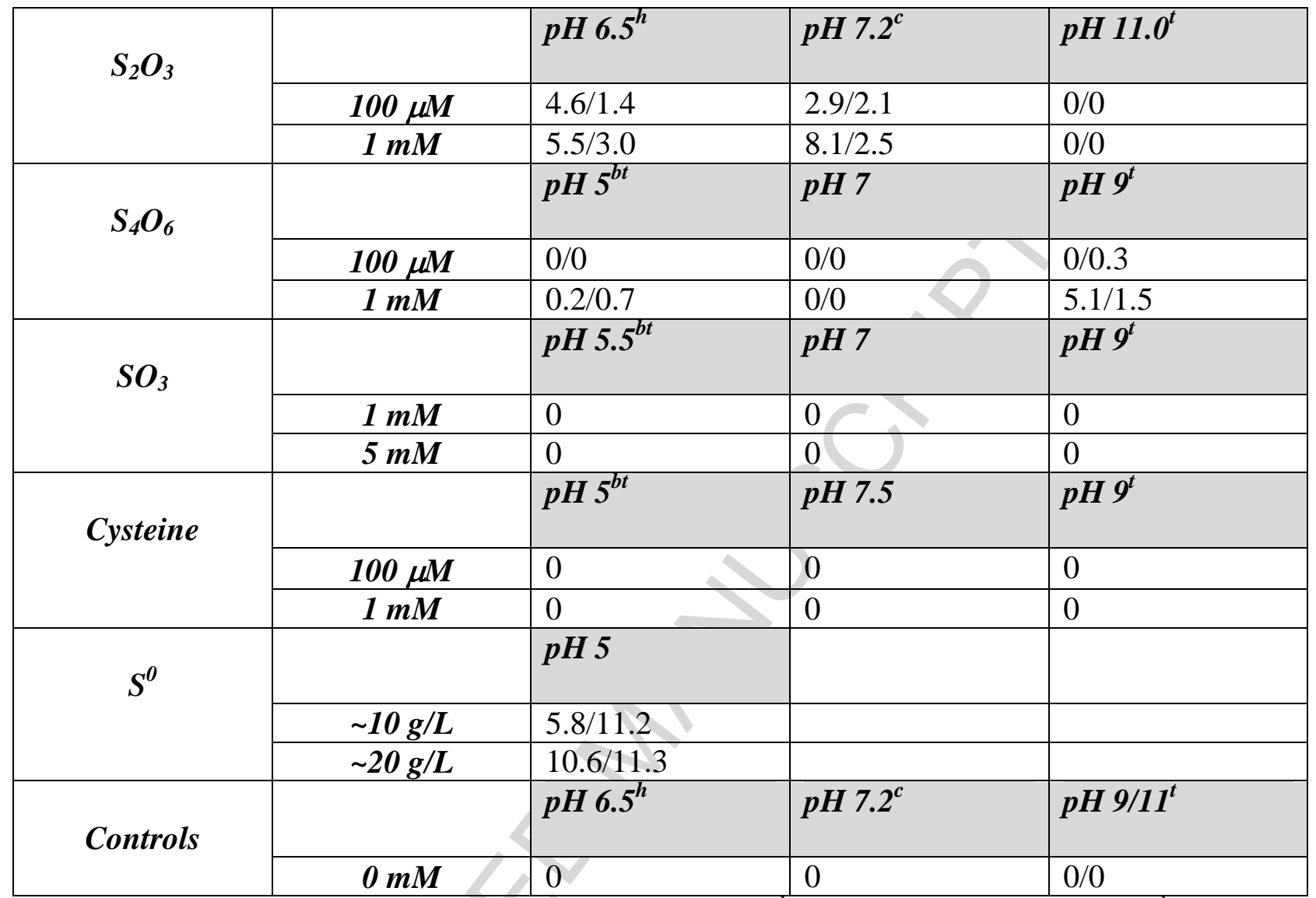

Non-neutral $\mathrm{pH}$ experiments were conducted in buffers: ${ }^{\mathrm{h}} \mathrm{HEPES},{ }^{\mathrm{c}}$ citrate-citric acid, ${ }^{\mathrm{bt}}$ Bis-Tris, ${ }^{\mathrm{t}}$ Tris. Neutral $\mathrm{pH}$ experiments were unbuffered. 

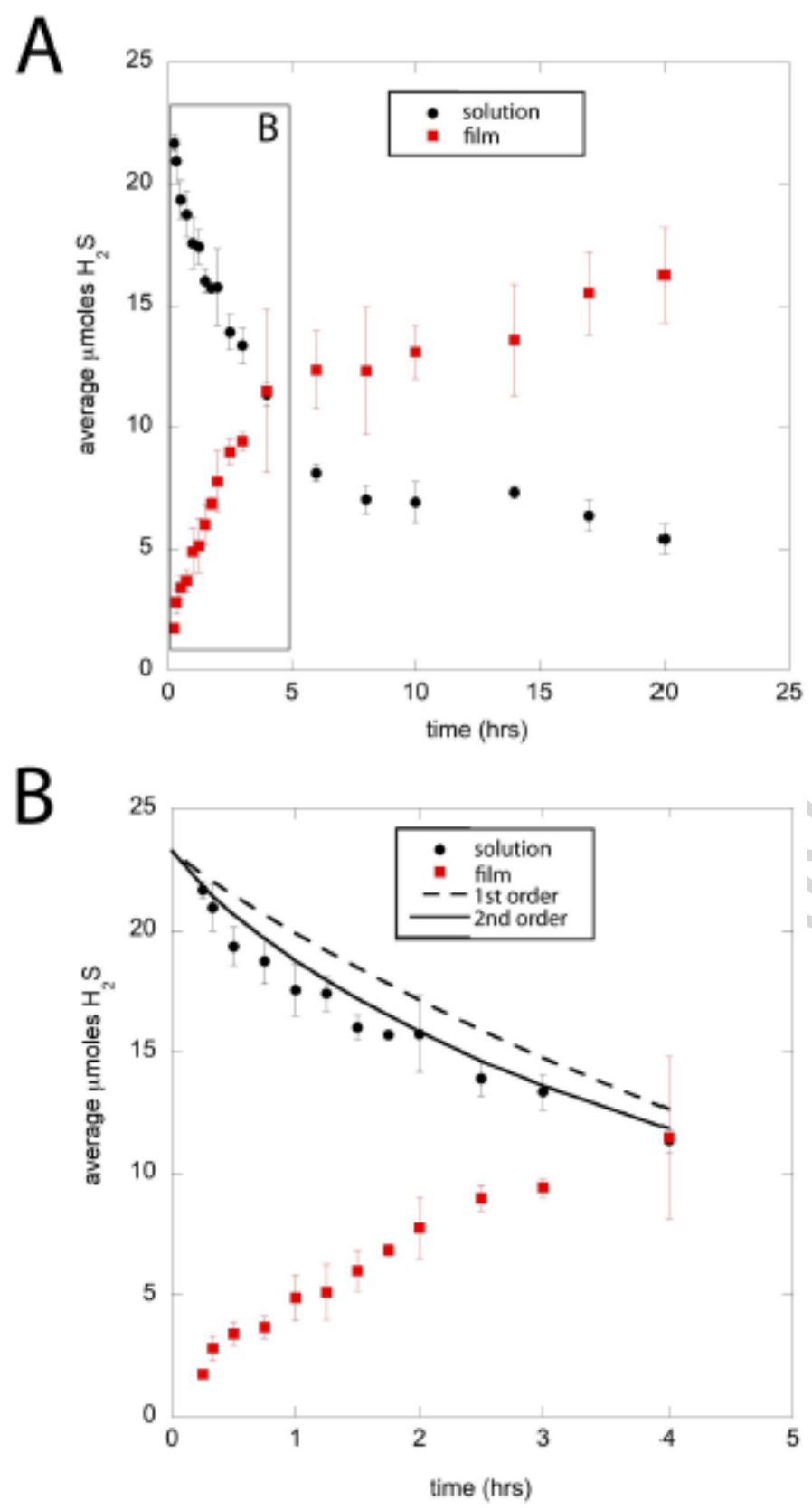

Fig. 1 


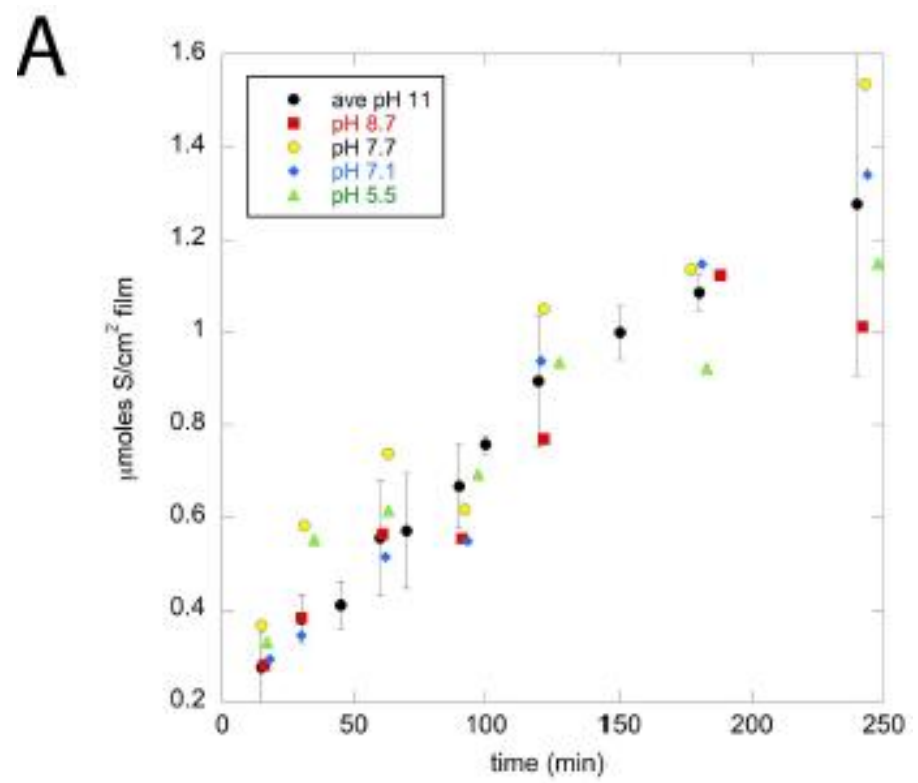

B

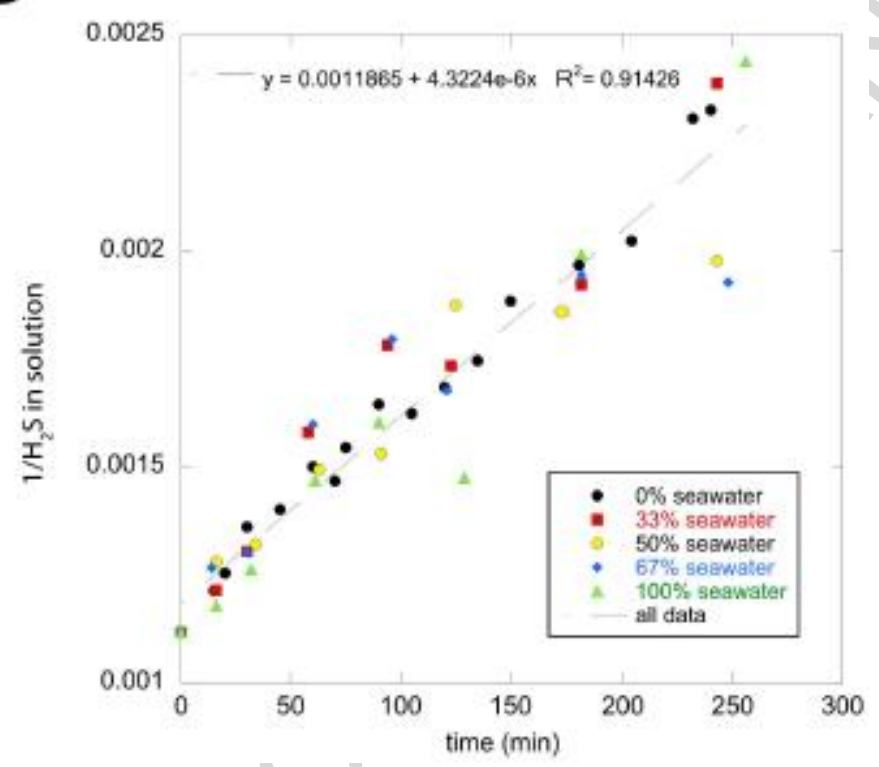

Fig. 2 


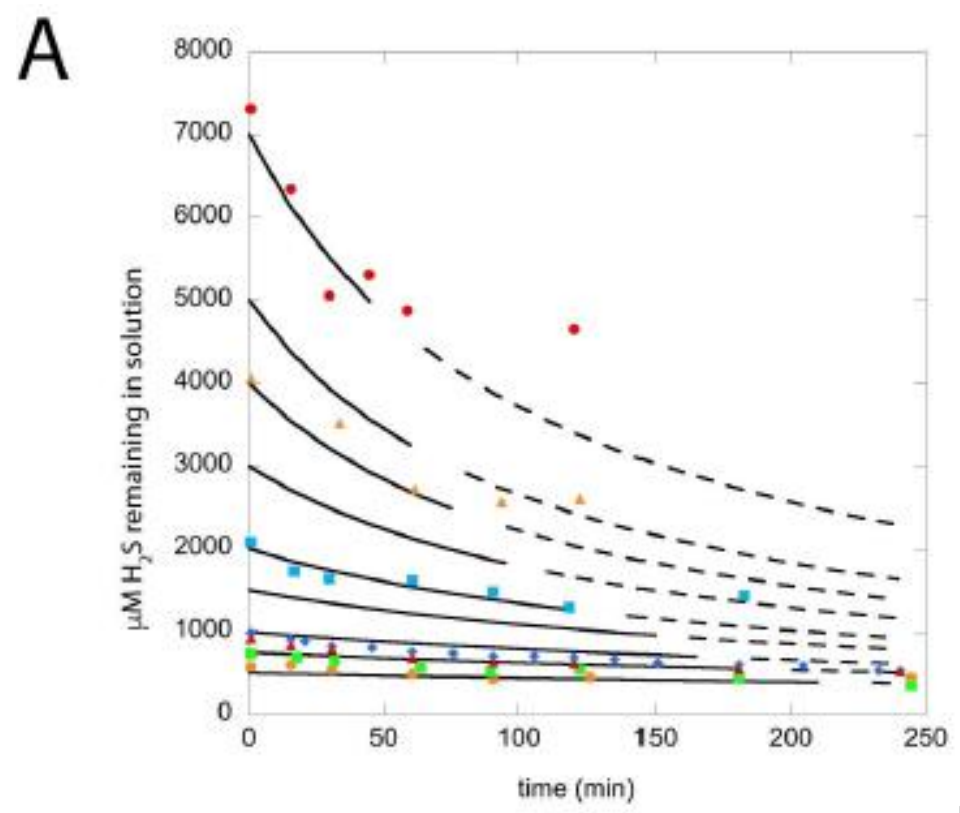

B

Fig. 3

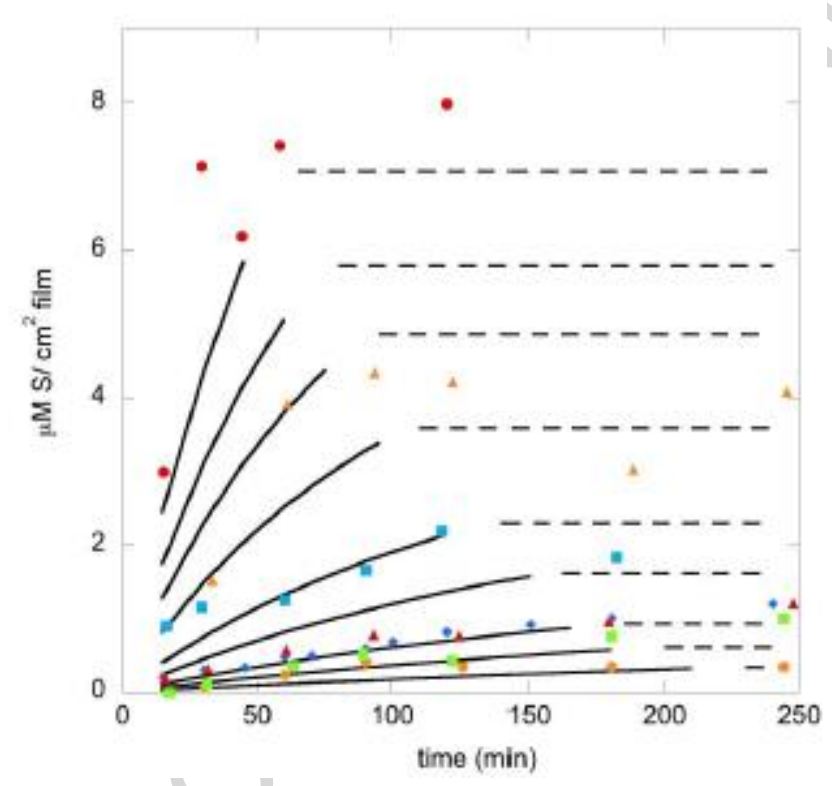




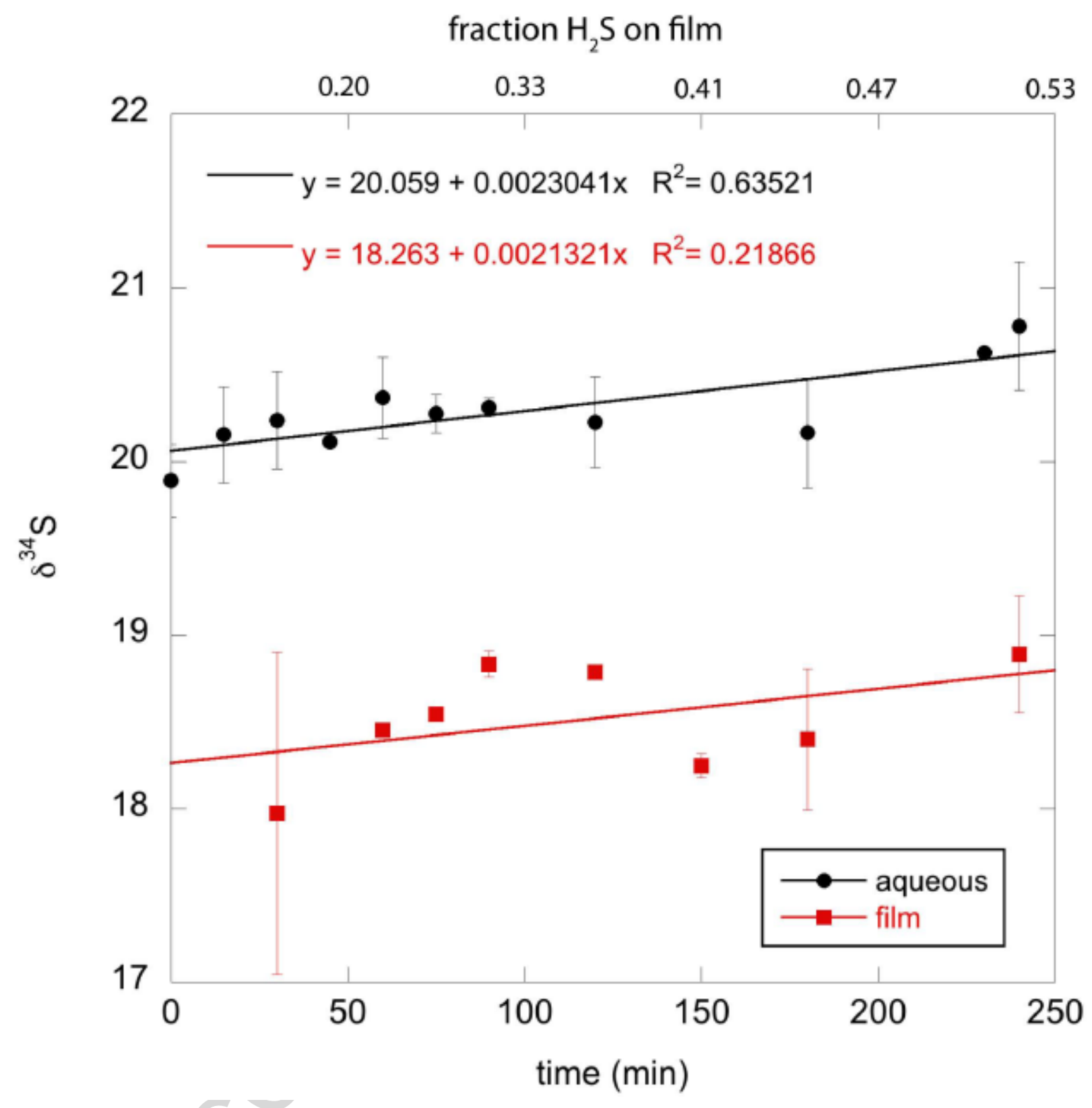

Fig. 4 


\section{ACCEPTED MANUSCRIPT}

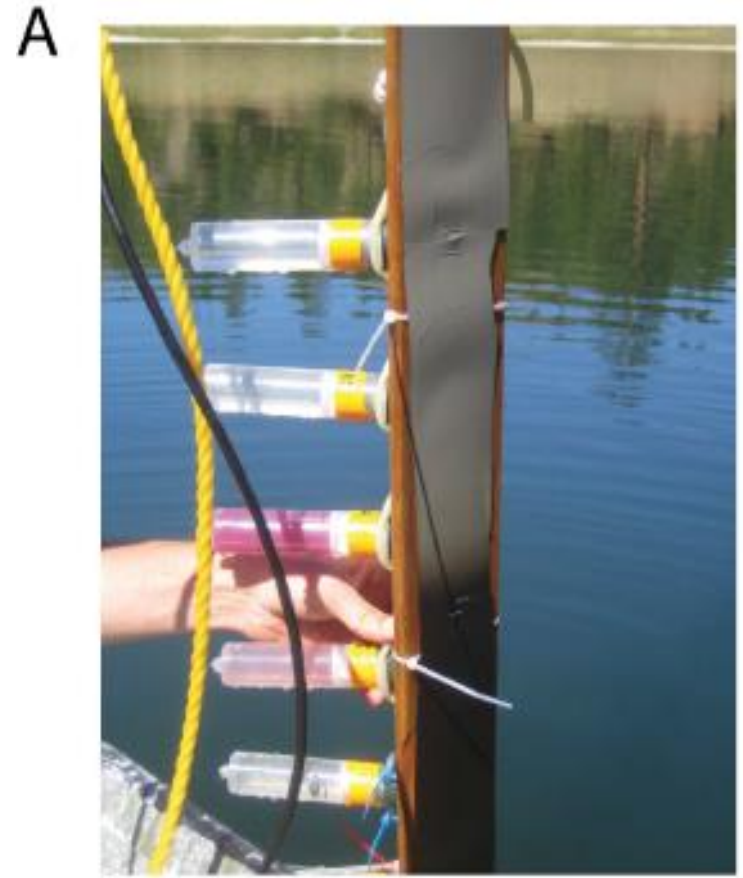

B

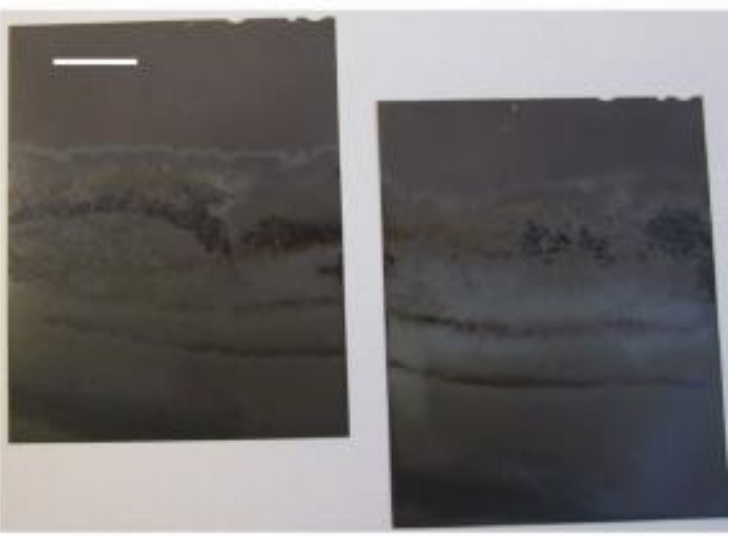

C

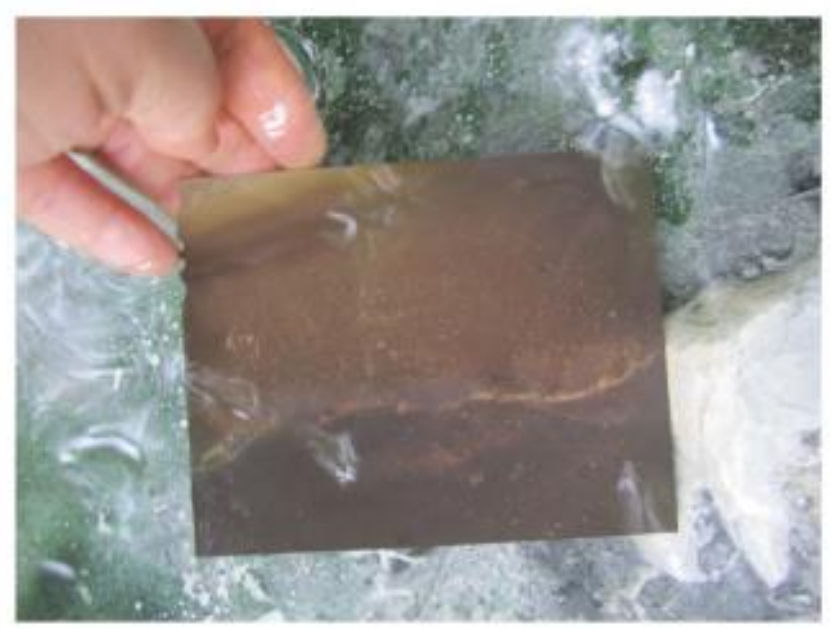

D

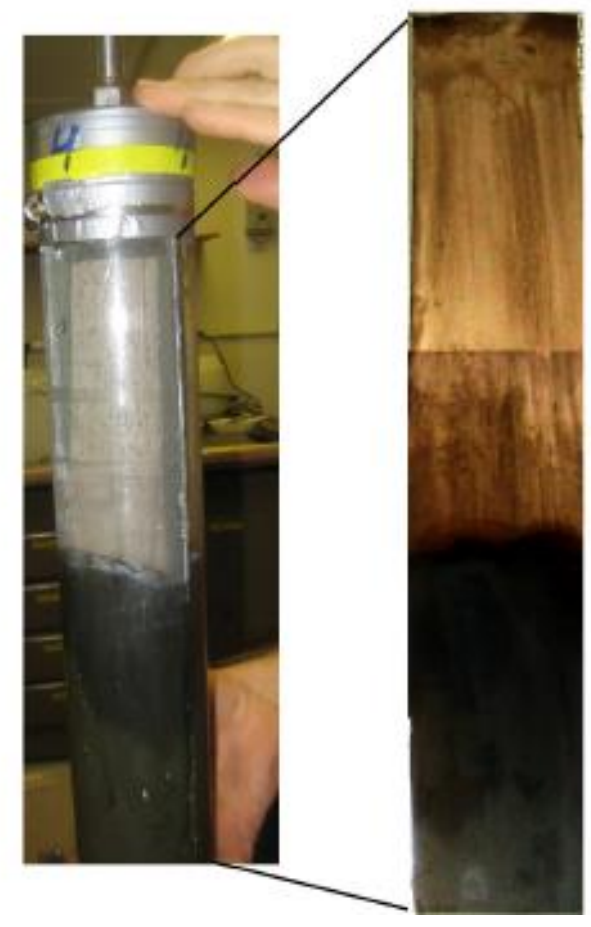

Fig. 5 
A

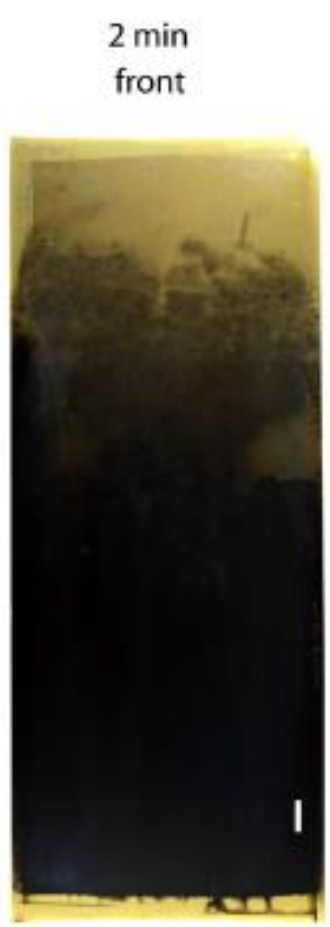

pmolsigfim

$\begin{array}{lllllll}0^{0} & 20 & 40 & 60 & 60 & 100 & 120\end{array}$

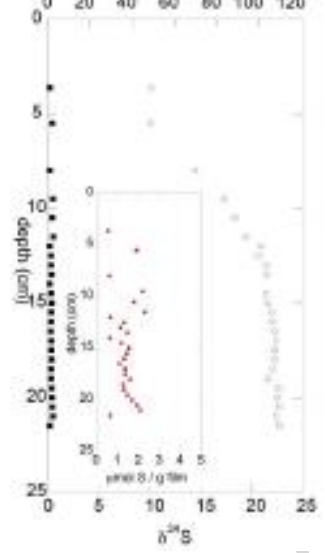

B

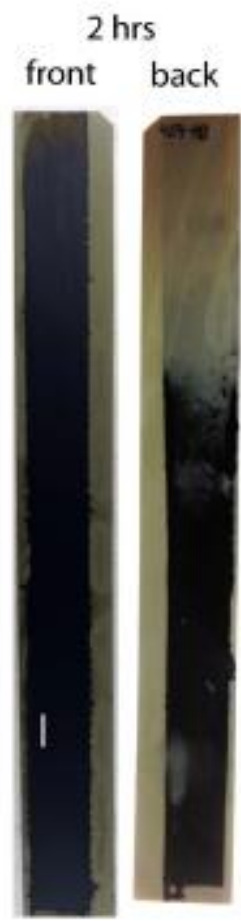

preal $S / \theta$ fim

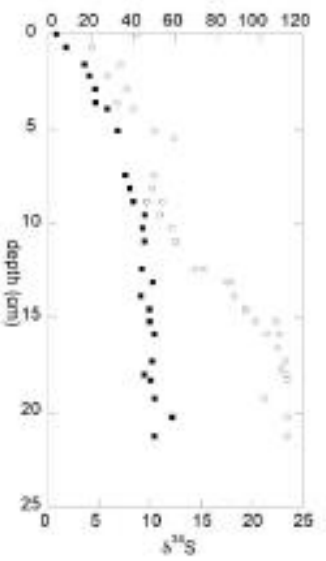

C

$4 \mathrm{hrs}$

front back
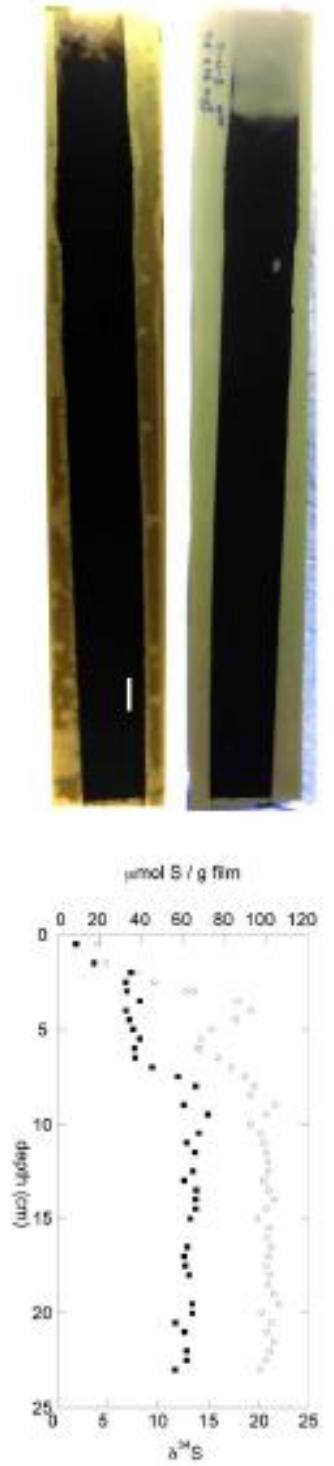

D

$24 \mathrm{hrs}$

front
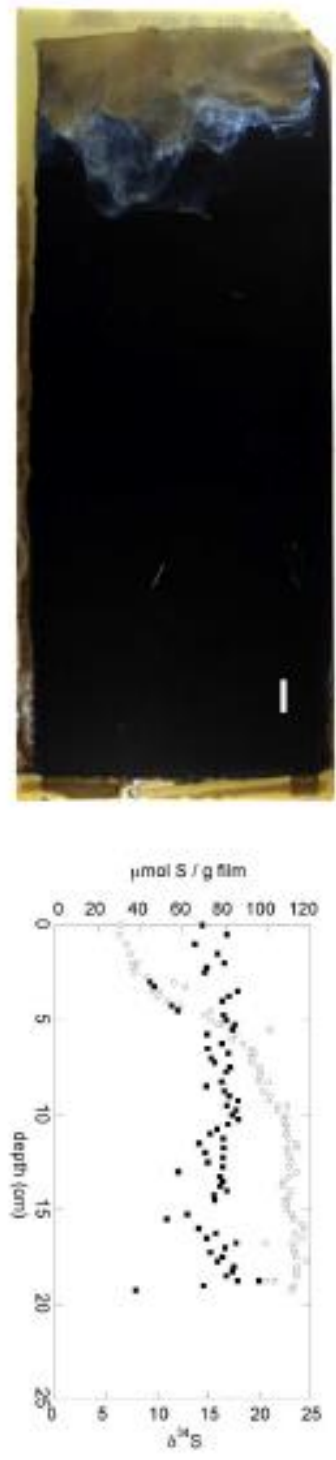

Fig. 6 
A

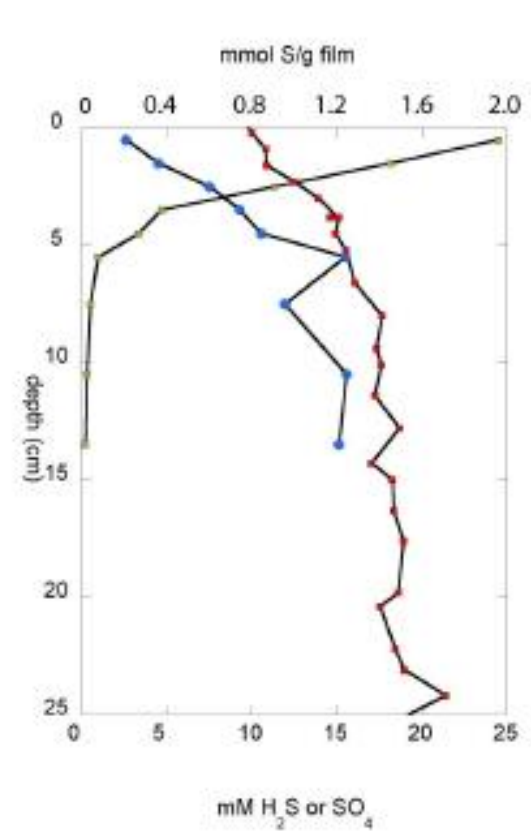

C

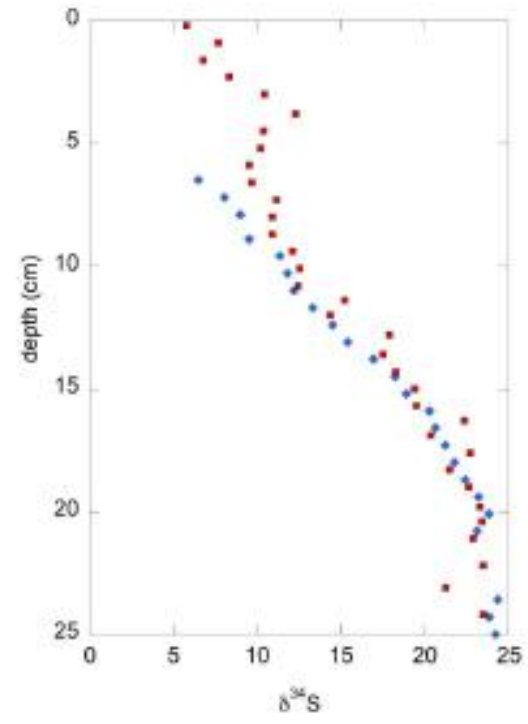

B

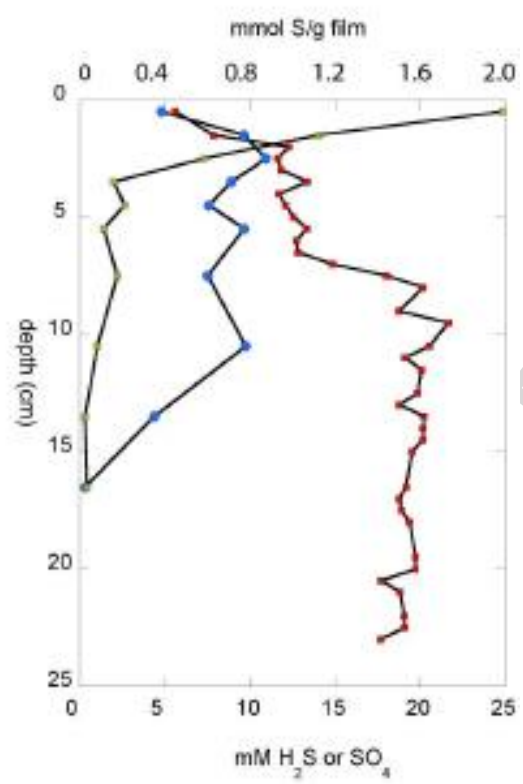

D

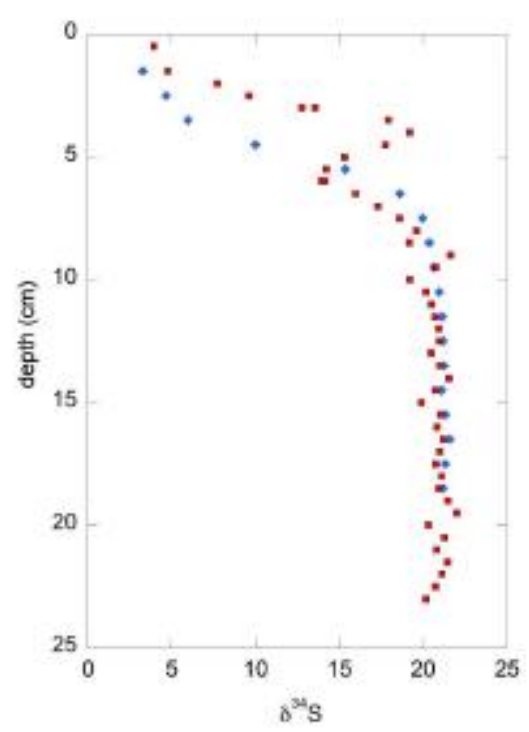

Fig. 7 

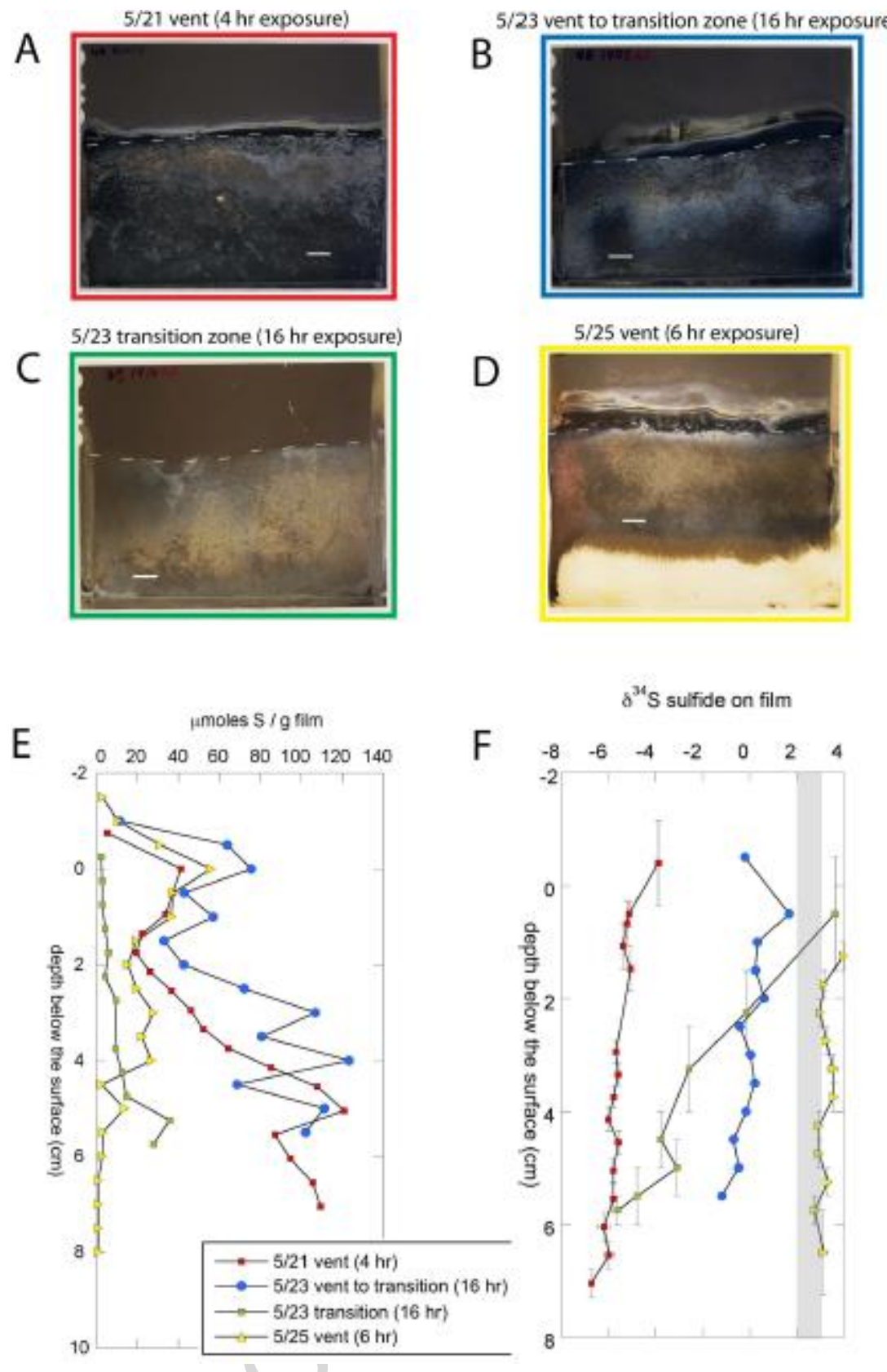

Fig. 8 


\section{Highlights}

- Photographic film can preserve ambient hydrogen sulfide distributions in sediments

- Uptake of sulfide on film follows second-order kinetics

- Captured sulfide reflects the $\delta^{34} \mathrm{~S}$ composition of ambient $\mathrm{H}_{2} \mathrm{~S}$, offset lower by $1.2 \%$ 